
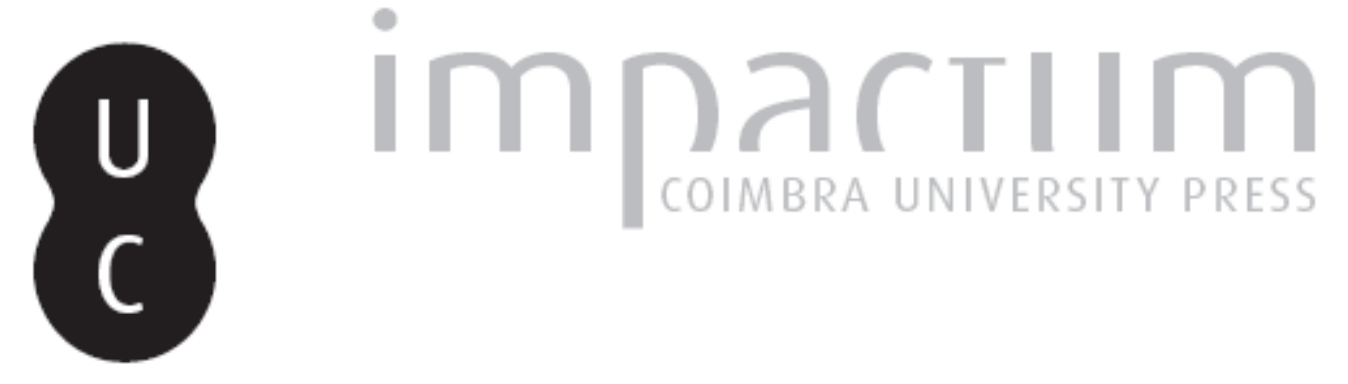

\title{
Inscripciones funerarias y votivas de Villardiegua y Pino de Oro: arqueología y epigrafía latina en Zamora
}

\author{
Autor(es): $\quad$ Beltrán, A.; Reher, G.; Alonso, F.; Romero, D.; Currás, B.; Pecharromán, \\ J. L.; Sastre, I.
}

Publicado por: Faculdade de Letras da Universidade de Coimbra

URL

persistente:

URI:http://hdl.handle.net/10316.2/37849

DOI:

DOI:http://dx.doi.org/10.14195/1647-8657_48_4

Accessed : $\quad$ 26-Apr-2023 11:42:59

A navegação consulta e descarregamento dos títulos inseridos nas Bibliotecas Digitais UC Digitalis, UC Pombalina e UC Impactum, pressupõem a aceitação plena e sem reservas dos Termos e Condições de Uso destas Bibliotecas Digitais, disponíveis em https://digitalis.uc.pt/pt-pt/termos.

Conforme exposto nos referidos Termos e Condições de Uso, o descarregamento de títulos de acesso restrito requer uma licença válida de autorização devendo o utilizador aceder ao(s) documento(s) a partir de um endereço de IP da instituição detentora da supramencionada licença.

Ao utilizador é apenas permitido o descarregamento para uso pessoal, pelo que o emprego do(s) título(s) descarregado(s) para outro fim, designadamente comercial, carece de autorização do respetivo autor ou editor da obra.

Na medida em que todas as obras da UC Digitalis se encontram protegidas pelo Código do Direito de Autor e Direitos Conexos e demais legislação aplicável, toda a cópia, parcial ou total, deste documento, nos casos em que é legalmente admitida, deverá conter ou fazer-se acompanhar por este aviso.

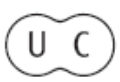


CONIMBRIGA

W.

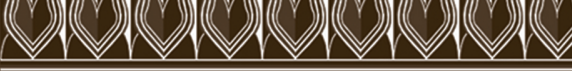

INSTITUTO DE ARQUEOLOGIA

VOLUME XLVIII • 2009

FACULDADE DE LETRAS 
A. Beltrán, G. Reher, F. Alonso, D. Romero, B. Currás, J.L. Pecharromán, I. SASTRE,

Instituto de História, CCHS. CSIC

INSCRIPCIONES FUNERARIAS Y VOTIVAS DE VILLARDIEGUA Y PINO DE ORO: ARQUEOLOGÍA Y EPIGRAFÍA LATINA EN ZAMORA

"Conimbriga" XLVIII (2009) p. 123-180

Resumen: Se presenta la epigrafía de Villardiegua de la Ribera y Pino del Oro (Zamora), dos localidades a ambas orillas del Duero. Es un conjunto inserto plenamente en el tipo de estela característico del occidente zamorano y reflejado en la epigrafía portuguesa de la vecina Bragança. Los estudios arqueológicos realizados en los últimos años han permitido ampliar notablemente el corpus, encuadrando esta epigrafía en un contexto histórico más detallado, dentro de la estructura de ocupación y explotación del territorio en época romana.

ABSTRACT: This article contains the collection of Roman inscriptions in Villardiegua de la Ribera and Pino del Oro (Zamora), two villages straddling both sides of the Duero. They correspond to the typical morphology of inscriptions in western Zamora, which also exists on the Portuguese side of the border, in neighbouring Bragança district. Archaeological research in recent years has enabled the significant expansion of the known corpus, offering it a more detailed historical context, within the occupational and exploitation strategy of the territory established by the Romans. 
(Página deixada propositadamente em branco) 


\section{INSCRIPCIONES FUNERARIAS Y VOTIVAS DE VILLARDIEGUA Y PINO DE ORO: ARQUEOLOGÍA Y EPIGRAFÍA LATINA EN ZAMORA}

\section{Introducción}

El occidente de la provincia de Zamora, y el territorio trasmontano vecino, tradicionalmente atribuidos a la civitas Zoelarum, se caracterizan por una notable concentración de epigrafía latina. Se trata de inscripciones que siguen el modelo más característico del occidente de la Península Ibérica, y que han sido objeto de análisis en los últimos tiempos por varios investigadores. Éstos han propuesto útiles esquemas de organización tipológica (Abásolo y García 1990; Lión 1989; Abásolo y Marco 1995; Navarro 1998) que continúan unos estudios epigráficos cuyas bases fueron puestas fundamentalmente por Le Roux y Tranoy, a los que se deben las primeras síntesis sobre la epigrafía del norte de Portugal (Le Roux y Tranoy 1984).

$\mathrm{La}$ aportación que proponemos en este trabajo pretende mirar la epigrafía a la luz del creciente conocimiento sobre organización del territorio y explotación de los recursos en la zona de Pino del Oro y Villardiegua de la Ribera (Zamora). Esta investigación, orientada por la perspectiva de la arqueología del paisaje, se centra en los procesos de cambio que puso en marcha la dominación romana y el papel de la minería del oro en ellos. Su desarrollo desde 2006 ha permitido la revisión y actualización del conjunto de inscripciones de Pino del Oro y Villardiegua, que ofrecemos en este trabajo. Al mismo tiempo, los primeros resultados están permitiendo vislumbrar factores de cambio histórico que, hasta el momento, no se habían considerado relevantes en esta región. Comprender el papel de la minería en la forma de 
organizar el territorio y las relaciones sociales es, sin duda, fundamental para entender la sociedad provincial y, por lo tanto, la información reflejada en la documentación epigráfica. Partimos de la base de que es necesario hacer converger el estudio epigráfico y el arqueológico puesto que el objetivo es la interpretación de los procesos históricos y no la mera descripción de sus restos materiales.

\section{Organización del poblamiento y explotación de los recursos}

Los estudios sobre el poblamiento en las comarcas de Aliste y Sayago están todavía en una fase inicial. Sin embargo, los trabajos emprendidos en su momento por Esparza (1986), así como los más recientes de González (2000) o Ramos (2003) para la comarca de Sayago, unidos a los resultados de nuestra investigación reciente, permiten empezar a caracterizar los modelos de organización del territorio prerromano y romano.

Pino del Oro y Villardiegua de la Ribera apenas distan unos kilómetros, pero se ubican en dos comarcas separadas por la profunda garganta formada por el Duero al discurrir por Las Arribes. Ya Plinio (N.H. IV, 35) consideraba al Durius frontera provincial entre la Tarraconense y la Lusitania. Sin embargo, el Duero no puede considerarse siempre una división, ni siquiera en Las Arribes, testigos de lo cual son los numerosos vados que tradicionalmente han salvado la barrera orográfica. Tampoco parece que lo fuera durante la Antigüedad, al menos en alguno de sus tramos. La civitas Banienses, incluida entre las lusitanas por la inscripción del Puente de Alcántara (CIL II 760), parece localizarse en la margen derecha del Duero según indicaría una inscripción encontrada en Torre de Moncorvo (Alarcão y otros 1990: $321)$.

Con respecto a la civitas Zoelarum, en la que teóricamente se insertaría la zona de estudio, si se admite la definición de Tranoy, englobaría los concelhos de Bragança, Vinhais, Macedo de Cavaleiros, Miranda do Douro, Mogadouro y Vimioso y, en territorio español, al menos la región de Aliste (Tranoy 1981: 52 y 159). Se trata de un territorio muy amplio, tal vez excesivamente, pero no improbable. Las similitudes geográficas y económicas de ambas zonas han sido 
remarcadas por diferentes autores, como es el caso de Gómez Moreno (1904: 5). Tanto en época prerromana como romana ambos lados de la frontera nos muestran procesos históricos muy parecidos (Esparza 1986; Sande Lemos 1993; Sastre 2001). Los problemas se plantean sobre todo para el caso de Sayago y, por lo tanto, para el caso de Villardiegua. Podría argumentarse que sería coherente desde un punto de vista administrativo que la zona se integrara dentro del conventus Asturum puesto que para las regiones del Noroeste en general, y del área astur en particular, se desplegó una infraestructura en torno a la actividad minera especialmente destacada. Pero también hay que tener en cuenta que existen otras regiones mineras en el Occidente meseteño ajenas, en principio, a la organización del Noroeste (Sánchez-Palencia y Ruiz del Arbol 1999). Se ha planteado la posibilidad de que Sayago sea zoela (Sastre 2002), pero dicha interpretación es sin duda problemática al ampliarse enormemente el territorio de una civitas ya de por sí grande. Por otra parte, la civitas Zoelarum no presenta únicamente las dudas relacionadas con la frontera interprovincial en la comarca sayaguesa. También una inscripción de Vigo de Sanabria (Zamora) ha sido interpretada como un testimonio de los zoelas (HEp 7, 1072), si bien otras interpretaciones no siguen esta lectura (García y Bragado 1997: 21-29).

La escasez de estudios arqueológicos en las regiones citadas no permite una interpretación detallada de los procesos sociales ocurridos durante y después de la conquista, pero sí es posible realizar una aproximación general a esta cuestión. Se conocen dos asentamientos que se han considerado de época prerromana, ambos emplazados sobre pequeños cerros rocosos con escasa superficie habitable. En Pino del Oro se encuentra La Ciguadeña, situado sobre los Arribes del Duero y justo encima de uno de los vados tradicionales del río. Su adscripción cronológica no deja de ser complicada debido a la escasa entidad de materiales encontrados en superficie (Esparza 1986, 103-104), mientras que su uso como campos de cultivo ha modificado por completo la fisonomía del asentamiento dificultando la localización de elementos defensivos. Pese a ello Esparza identifica una línea de muralla defendiendo la zona noreste del asentamiento (1986: 103-104). En el caso de Villardiegua nos encontramos con el yacimiento de San Mamede/ 
Peña Redonda, al igual que en el caso anterior se encuentra sobre la caída de Los Arribes del Duero y próximo a un vado que cruza el río. No se ha identificado ningún sistema defensivo en el castro y su adscripción cronológica se establece en la Segunda Edad del Hierro debido a la aparición de material celtibérico.

En cuanto a asentamientos romanos, de nuevo tenemos dos conocidos: San Mamede/Peña Redonda, que presenta una ocupación continuada, y El Picón/Sancil. El asentamiento de San Mamede/Peña Redonda tiene una continuidad demostrada hasta finales del siglo IV o principios del siglo $\mathrm{V}$ por los materiales arqueológicos encontrados en el asentamiento. El sistema de ocupación es difícil de establecer debido al uso como campos de cultivo del yacimiento, pero parecen existir una serie de aterrazamientos entorno al asentamiento que podrían corresponder a momentos antiguos. El caso de Pino del Oro es diferente, el asentamiento romano se encuentra en el Picón, un cerro a 500 metros al Sureste del municipio actual. Este asentamiento se localiza en una zona de perfecto control de zonas de cultivo, al Sur y Sureste, así como de la zona minera, al Oeste del asentamiento, subiendo el arroyo de Fuentelarraya que se sitúa a sus pies. Las últimas labores realizadas tanto de prospección como de excavación arqueológica nos muestra una cronología que se situaría desde los primeros momentos del siglo I d. C. hasta al menos finales del siglo IV o principios del siglo V d. C. El tipo de material y el sistema de construcción doméstico documentados, claramente "romanos", reafirman el fuerte cambio que se produce tras la conquista romana. Así mismo, estos dos asentamientos romanos se encuentran en unas zonas privilegiadas de acceso a las explotaciones mineras.

Otro elemento esencial para comprender la nueva implantación romana es la red viaria. Las vías conocidas a través de los itinerarios conservados pasan a bastante distancia de esta zona. Por un lado la Vía 17 discurre atravesando el territorio zoela por su parte noroeste (Itin. Ant. 423, 1-2). Por otro, la vía 24/26 cruza el Duero bien por Zamora, bien por Alba de Villalazán (Itin. Ant. 434, 6; Moreno Gallo 2006: 6162). Esta última, conocida también como la "Vía de la Plata", ha generado en el pasado algunas interpretaciones excéntricas que la hacía pasar por la zona de estudio. La más destacada es la identificación de Pino del 
Oro con Vico Aquario (Itin. Ant. 439, 9; Corzo 1986). Esta interpretación supone un problema por varias razones que incluyen la falta de testimonios arqueológicos y de miliarios, tan abundantes en los pasos del Duero más orientales, sin contar las distancias de los itinerarios, que no parecen coherentes con esta alternativa occidental.

Sin embargo sí hay algunos testimonios potenciales y variadas hipótesis que establecen una vía vadeando el Duero en esta comarca, caso de la "Calzada Mirandesa" (Sevillano 1970: 475). Ésta cruzaría Sayago por Moralina hasta Villadepera, y continuaría hasta cruzar el río y, pasando por Pino, enlazaría con otra vía presumiblemente vertebrando Aliste desde Ricobayo hasta la Vía 17 cerca de Bragança. En Villadepera se desviaría un ramal que, pasando junto a San Mamede/Peña Redonda, cruzaría los escarpados bordes del río hasta Aldeia Nova.

La riqueza aurífera existente en esta zona es con seguridad uno de los factores más importantes en la implantación imperial romana en este territorio. Como se puede observar, la llegada de Roma supuso un cambio completo en Pino del Oro y Villardiegua de la Ribera, tanto en la morfología de los asentamientos, en la forma de articular el territorio y en las prioridades, también, a la hora de explotarlo. Así mismo, también apareció la escritura monumentalizada en forma de inscripciones.

\section{Las inscripciones latinas}

La epigrafía es, ante todo, indicador de un profundo cambio social. A través de ella se hacen visible un nuevo universo simbólico, ya sea cultual, ya sea funerario, que ocupa su sitio particular en la nueva configuración del espacio. Casi todas las inscripciones estudiadas en esta zona son funerarias. Lamentablemente este tipo de inscripciones no se han localizado in situ, ni se han documentado aún las necrópolis. Es probable que las estelas formaran parte del paisaje rural marcando el espacio de los muertos en los accesos a los asentamientos. De esta manera se haría muy visible el cambio entre época castreña y romana, ya que no tenemos testimonio del mundo funerario prerromano - algo generalizable a todo el Noroeste $-\mathrm{y}$ sí lo tenemos, y abundante, del romano. El efecto de la epigrafía sobre sociedades ágrafas no es un tema que haya suscitado reflexión en la línea de los estudios sobre la relación entre oralidad y 
escritura (Ong 1982; Goody 1986; Olson 1994). Queremos, sin embargo, llamar la atención sobre la importancia histórica de este fenómeno y de todas las implicaciones culturales que implica, sobre todo su imbricación en las relaciones de poder.

Las estelas pertenecen al "estilo de Picote". Se trata éste de un término acuñado por Le Roux y Tranoy para definir un tipo de inscripciones cuyo centro difusor se localiza, según estos autores, en la región de Miranda do Douro y se expande hacia Bragança, por un lado, y hacia Zamora por el otro (Le Roux y Tranoy 1984: 37 ss.). La estela típica incluye varios registros superpuestos: cabecera semicircular con rueda radiada, cartela con inscripción, franja con decoración zoomorfa y serie de arquerías o estrías. A partir de aquí la variedad es amplia, tanto en los motivos como en la inclusión o ausencia de algunos registros (Abásolo y García 1990). En el caso zamorano, por ejemplo, es casi inexistente la decoración zoomorfa. Algunos autores prefieren restringir el concepto "estilo de Picote" a determinadas inscripciones, sobre todo en mármol, de la región portuguesa (Navarro 1998). Nosotros consideramos que puede manejarse con un sentido más general. Podría emplearse la alternativa "estelas con rueda de radios", por ejemplo, pero se perdería esa idea de difusión desde un centro en Picote que es de enorme interés histórico y que habrá que revisar en el futuro.

Así mismo, la presencia de la rueda de radios, que es considerada el elemento más característico (y el que mejor se ha conservado en muchos casos), no debe ocultar un hecho destacable, a saber, el marcado carácter arquitectónico de la disposición formal de estas estelas. El eje de la estructura, el punto en el que se sitúa la inscripción propiamente dicha, suele ser la representación de un espacio arquitectónico, habitualmente conformado por dos columnas que sujetan, en algunos casos, un arquitrabe o balconada. La carencia de frontón es un hecho en sí significativo, ya que éste tiende a enfatizar ese contexto monumental, como ocurre en las estelas oikomorfas de, por ejemplo, Lara de los Infantes (Burgos), que constituyen verdaderos templos exentos (Abásolo 1973 y 1977). A pesar de reconocer las columnas jalonando la cartela o las arcadas del pie de inscripción (Abásolo y García 1990), la simplificación de las trazas arquitectónicas en el tipo de inscripción aquí estudiado ha hecho que este elemento se considere secundario. 
La morfología de las estelas de Pino y Villardiegua puede encuadrarse sin problemas en la tipología definida por Abásolo y García Rozas para el caso zamorano general. Así lo hemos indicado en el catálogo. Existen, sin embargo, dos casos que presentan cierta particularidad. Se trata de PO 8 y PO 10. Se caracterizan por ser bipartitas, tener la rueda rebajada y la cartela flanqueada por columnas. Estas inscripciones podrían adscribirse teóricamente o bien al grupo I o bien al IV definidos por los autores citados. Pero estas posibles adscripciones tienen una connotación cronológica clara. Abásolo y García consideran al grupo I en general como temprano, o al menos más temprano que el grupo IV que es definido como tardío. Por ello, preferimos abstenernos de indicar una tipología concreta.

El tipo de onomástica responde mayoritariamente a un formulario sencillo consistente en nombre del difunto + filiación + edad. No está constatado el uso de consagración a los dioses manes ni de fórmulas funerarias finales, a excepción de PO3 y PO6, inscripciones muy particulares en comparación con el resto. La antroponimia en sí se puede considerar «indígena», con presencia tanto de nombres atestiguados en diferentes zonas de Hispania, como los casos de Ambatal-us o Totonus, como de nombres de uso local o regional como los casos de Docia/-us o la variante local del nombre Reburrina, muy habitual en toda la península, que sólo en esta zona lo encontramos con la grafía Reburina. Los casos aparentemente únicos son analizados en el catálogo.

Un caso aparte lo constituyen los nombres que aparecen en PO 3 y PO 6. Estas estelas presentan varias peculiaridades. En primer lugar el material en el que están hechas es diferente ${ }^{1}$. Ambas piezas estaban realizadas en "mármol de Santo Adrião" o "brecha", frente al resto que están hechas todas en granito. Esto de por sí ya les otorga una categoría diferente, que parece apuntar hacia un mayor nivel y calidad. Ambas piezas se hallaron dentro del término de Pino del Oro. No se ha documentado ninguna pieza similar en Villardiegua de la Ribera. Podemos esbozar dos interpretaciones. Por una parte, que estemos ante una jerarquización dentro de los grupos que acceden al hábito epigráfico

\footnotetext{
${ }^{1}$ A pesar de que la inscripción PO 3 se encuentra en paradero desconocido, su similitud a la pieza PO 6 justifica un analisis conjunto.
} 
en estos ámbitos rurales. A las diferencias en el material se unen también divergencias onomásticas. Los nombres de estas inscripciones corresponden a una onomástica "latina" y a su vez presentan los únicos casos en ambas localidades en los que el varón presenta dua nomina, frente a los nombres únicos del resto de las piezas. Podría tratarse, por lo tanto, de gentes, los Domitii/Aurelii y los Calpurnii que harían resaltar su mayor poder económico o su mayor nivel social frente al resto de la población. Bragado es de la opinión de que estas estelas se habrían realizado en talleres del valle de Vidriales. Esto nos daría otra pista sobre el poder adquisitivo de esta familia que puede importar este epitafio frente al resto de población que los adquiriría en talleres locales (Bragado 1996: 13). De todos modos este tipo de piezas no presenta muchos paralelos en la provincia, uno en Villalcampo ( $H A E$ 891) y uno en Santibáñez de Vidriales ( $A E$ 1976, 290b), si bien son algo más habituales en la zona portuguesa.

Sin embargo es posible también otra interpretación basada en la cronología. Las dos inscripciones en cuestión presentan otra diferencia frente al resto: la presencia de la fórmula de consagración a los dioses Manes, con la abreviatura $D M$, sin abreviatura $S$ (acrum). La adprecatio a los Manes es característica y exclusiva de los tipos II y III, tardíos, de Navarro Caballero (Navarro 1998: 185-90). En la parte final de la inscripción también aparece una formula idéntica en ambos casos, con el uso de la expresión filio carissimo memoria, antes de la mención de edad, que indica una datación tardía (Pérez Rodríguez-Aragón, 1993: 183-184). El hecho de que en PO 6 aparezca a ambos lados del epitafio principal los nombres de los padres, y que el nombre completo del padre Domitius Proculus sea abreviado sólo en Proculus podría indicar un fenómeno tardío que situaría la estela a mediados del siglo III, relacionado con el edicto de Caracala (Navarro 1998: 189). El nombre del hijo, Aurelius, abundaría en esta idea. De hecho tal vez estemos ante un cambio de gentilicio.

La mayor calidad de estas estelas "en brecha" y todo lo que se deduce de la onomástica y la morfología de las mismas podría indicar un cambio en la configuración de los grupos dominantes, en el caso de que estas inscripciones sean más tardías que la mayor parte de las demás. Coincidiría este fenómeno precisamente con el supuesto momento de declive de la minería estatal, cuando la crisis del sistema monetario y la 
pérdida del patrón oro llevaría a la paralización de muchas explotaciones mineras, sobre todo aquellas que necesitaban de enormes infraestructuras y de un control centralizado del territorio a escala suprarregional (Sánchez-Palencia ed. 2000). ¿Fue este el caso de las minas de Pino de Oro?, en principio parece coherente que así sea, pero aún no podemos afirmarlo.

\section{La epigrafía rural del occidente de Zamora: relaciones sociales y realidades simbólicas provinciales.}

Como ya se ha dicho, el occidente de Zamora destaca por la abundancia de inscripciones que responden a una tipología unitaria ("estilo de Picote") con una enorme variabilidad formal. Sin embargo esta ruralidad y el carácter poco clásico de las inscripciones se han interpretado como un rasgo retardatario y de escasa "romanización", quedando oculto el cambio profundo que se deduce de la organización del territorio y la sociedad. Las inscripciones, sobre todo las que muestran onomástica peregrina y/o indígena, son consideradas fruto de un grupo social sin aspiraciones políticas, sumergido en el ámbito de las necesidades de subsistencia cotidiana, y cuya participación "en la vida social romana" se hace "de forma pasiva" (García Martínez 1999: 21). Estos hacen inscripciones votivas a sus "dioses favoritos" y lápidas funerarias "para sus seres queridos" en un extraño alarde de indiferencia frente a lo romano, sobre todo teniendo en cuenta un contexto rural en el que la tasa de analfabetismo seguramente superaba el noventa por ciento.

Ya hace tiempo que se ha propuesto considerar el hábito epigráfico como un síntoma claro de un profundo cambio cultural, y su relación con grupos dominantes locales también se ha puesto ya de manifiesto: "ce serait sans doute faire une erreur que de classer parmi les milieux modestes les personnes qui font réaliser ces stèles, même si les monuments ne présentent pas toutes les qualités idéales dans la facture et dans la gravure. Il existe tout un milieu de notables établis en zone rurale" (Tranoy 1984: 271). Ya hace tiempo, también, que se destacó el carácter rural de esta epigrafía como uno de sus rasgos característicos (Le Roux y Tranoy 1984). Brevemente puede añadirse que las inscripciones forman parte de un nuevo paisaje social; un paisaje marcado 
por relaciones de desigualdad condicionadas por el imperialismo, en las que el uso de la escritura epigráfica se convierte en una herramienta más en la configuración de la nueva formación social. Un rasgo de identidad de grupo que reinterpreta una tradición y la pone al servicio de las nuevas relaciones sociales (Sastre 2002).

Basta sólo con tener en cuenta el contraste en las prácticas funerarias de las formaciones sociales de la cultura castreña y de la época provincial, algo que a escala general es aplicable también a estas regiones zamoranas. El registro funerario castreño es inexistente. Y esto no se debe a un problema de práctica arqueológica que se resolverá en un futuro, "cuando por fin aparezca". Es una realidad debida a que las prácticas funerarias de los grupos castreños, fueran cuales fueran, no han dejado una huella arqueológica convencional. Esto es un dato por sí mismo (Alonso e.p.). Con otras prácticas cultuales o rituales ocurre lo mismo. Sin embargo, tras la conquista se produce en estas regiones un cambio radical en el que la escritura es protagonista.

Para una lectura en clave simbólica de las estelas que nos ocupan ${ }^{2}$, creemos que debemos partir del registro arquitectónico central que envuelve la identificación escrita del fallecido (un esquema básico consistente en nombre+filiación+edad, sin lugar para al adprecatio a los Manes o fórmulas finales). Las columnas con los capiteles muy marcados (más elaborados o menos) encuadran el epitafio por la parte superior a través de lo que podría ser una especie de arquitrabe, en algunos casos con un frontón simplificado (como en PO-07, Fig. XL) o una especie de balconada (como en VR-18, Fig. XXI, VR-19, Fig. XXII; PO-01, Fig. XXXIII). En nuestra opinión, este espacio arquitectónico, que contiene únicamente el epitafio en nuestros casos, simboliza el locus sanctus del difunto. Como si de un templo se tratase, el espacio arquitectónico grabado en piedra consagra al fallecido, haciendo ver a los ojos de todos que esa estela funeraria indica simbólicamente un lugar sagrado (MacCormack 2003). La centralidad de este elemento se ve enfatizado por la presencia de la escritura, siendo el nombre el elemento esencial en torno al que se articula el hábito epigráfico, como por otra

\footnotetext{
${ }^{2}$ Hemos tenido en cuenta las estelas-tipo de esta zona, que son obviamente mayoritarias dentro del registro conservado, dejando a un lado el caso de las estelas en brecha.
} 
parte es característico de la epigrafía latina (Corbier 1991: 114-5). Esta realidad resulta aún más significativa si se tiene en cuenta el alto grado de analfabetismo que hemos de suponer para estas regiones durante todo el Alto Imperio, y el carácter simbólico que debió tener el hecho mismo de la escritura, más allá de la transmisión del mensaje escrito (Sastre 2002). El hecho de que existan estela bisomas o trísomas puede explicarse en esta misma dirección, y puede indicar que cada difunto requiere un espacio propio.

Sobre este espacio central escrito, orbita la bóveda celeste, representada por el acabado semicircular de la cabecera que incluye al remarcado elemento astral. A su vez, por debajo, se suceden las características arcadas arquitectónicas, que siguiendo nuestro esquema podrían simbolizar las Puertas del Inframundo, como han indicado ya otros autores (Nagy 1934: 236; Cumont 1942: 73 ss). El hecho de que la estela quede hincada en la tierra también permitiría sustentar esa vinculación del sector inferior con el infierno, aún en aquellos casos en los que no se incluyan explícitamente arquerías.

A diferencia de cualquier supervivencia prerromana o céltica en el aparato simbólico de estas estelas, nosotros consideramos que el hilo conductor habría sido el romano y no las presuntas similitudes prerromanas. Hay que partir de la base de que los referentes directos de la difusión del hábito epigráfico en el Noroeste son dos: las inscripciones imperiales (la llamada "epigrafía inducida", Pereira 1995) y los epitafios de los militares trasladados al Noroeste por la conquista. Estos son referentes esenciales para entender el papel social de la epigrafía, como ya se ha defendido en otras ocasiones y también la propia configuración morfológica de las inscripciones que, por encima de hipotéticos referentes célticos (Le Roux y Tranoy 1984: 38), posiblemente tienen una base militar muy marcada (Abásolo y Marco 1995). No hay que olvidar que las estelas de otras regiones militares, como Nórico y Panonia, presentan características formales y asociaciones simbólicas semejantes (vid. Nagi 1934 XLVIII-1 o XLIX-1).

Así mismo, esta tipología unitaria del Occidente hispano, por encima de la diversidad formal, nos indica la existencia de unos grupos dominantes que se identifican entre sí a escala regional, y comparten unos repertorios bastante unificados, reflejo de su particular inserción en el contexto general del imperio. 
En estudios anteriores planteábamos la existencia de diferencias entre la epigrafía de regiones como el Bierzo y de otras como las de los zoelas o vadinienses en función de la presencia de la minería de oro (Sastre 2002). Parece que esta cuestión hay que matizarla a la luz de los últimos resultados. Las diferencias siguen siendo claras: las inscripciones de la región berciana parecen estar mejor integradas en las redes de relaciones políticas regionales (tipologías más clásicas, abundancia de onomástica ciudadana desde el siglo II, existencia de un flamen provincial en Tarraco - RIT 333- con origo Bergidoflaviensis, etc.), mientras que la epigrafía zoela resulta ser más localista, sobre todo en el ámbito zamorano y bracarense -algo menos en el mirandés(onomástica indígena, multiplicación de nombres, relativa abundancia de nombres únicos...). Ambas son zonas con extracción de oro. Posiblemente la clave no esté en la presencia o ausencia de minería, sino en la ejecución de técnicas extractivas diferentes, a mayor o menor escala, con lo que la participación de los grupos dominantes y de las civitates locales en el proceso productivo pudo ser también diferente.

La epigrafía no constituye únicamente un registro de nombres y teónimos, fórmulas y formularios. Es un elemento de cultura material escrita. Las inscripciones deben interpretarse y contextualizarse dentro del proceso histórico de cambio social propiciado por el factor imperialista de explotación minera. Dicho de otra manera, la epigrafía es un registro que nos habla de la sociedad, ya que es fruto de su construcción, y, también, factor en la configuración de su universo simbólico.

NOTA FINAL: en el momento en que se envió este artículo para su publicación se documentó en el asentamiento de El Picón (Pino de Oro) una tabla de bronce que recoge un documento jurídico. Se ha publicado en Sartre, Beltrán y Sánchez - Palencia 2009. 


\section{Villardiegua de LA Ribera}

\section{VR- 01 Cabecera de estela}

\section{(Fig. I)}

Ubicación actual: En la casa llamada "Los Arcos", propiedad de J. Manuel Magarzo Pintado, "Manolo", y M. N. Blanco Alfonso, en la c/Verónica 4. Embutida en un murete en la entrada de coches.

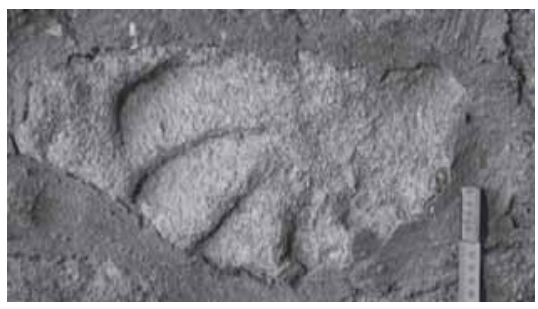

FIG. I

Procedencia: No especificada.

Dimensiones y material: (19) x (34) x $? \mathrm{~cm}$. Piedra granítica blanca.

\section{Morfología:}

Cabecera: rueda en relieve de $15 \mathrm{~cm}$ de radio en la que se ven 6 de 18 (aprox.) rayos dextrógiros.

Tipología ${ }^{3}$ : IV C

Bibliografía: Inédito

VR-02 Estela funeraria (Fig. II)

Ubicación actual: En casa llamada "Los Arcos", propiedad de J. Manuel "Manolo" Magarzo Pintado y M. N. Blanco Alfonso, en la c/Verónica 4. Embutida en un murete en la entrada de coches.

Procedencia: No especificada. Posiblemente del castro de San Mamede. Dimensiones y material: (40) $\times 37 \mathrm{~cm}$; Campo Epigráfico (18) x 27cm; Altura

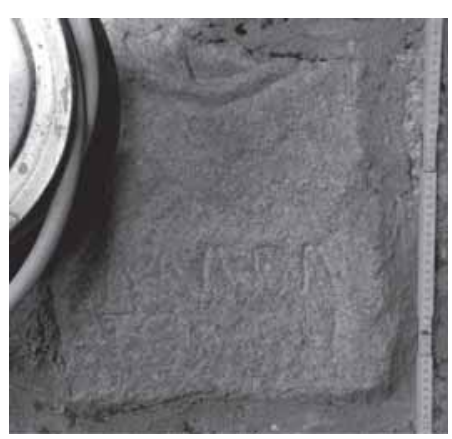

FIG. II de las letras $5,5 \mathrm{~cm}$. Granito de naranja-beige claro.

Morfología:

\footnotetext{
3 Según Abásolo - García Rozas, 1990,
} 
Cabecera: rueda en relieve de $10 \mathrm{~cm}$ (aprox.) de radio en el que se ven 23 rayos dextrógiros, de un total de $8-10$. Se encuentra roto en su parte superior, faltando tres cuartas partes de la cabecera.

Cuerpo: liso, sin molduras.

Pie: pieza lisa con una rotura horizontal a una altura indeterminada.

Transcripción y desarrollo: Amba/ to / . . . . -

Interpretación: Ambato, hijo de....

Comentario: Es de suponer que falte, posiblemente, una tercera línea con la edad del difunto e incluso con la filiación. Ambato es un nombre habitual en toda Castilla y León, con ejemplos en Ávila (HEp 4, 1994, $72=H E p O L$ 15456), Salamanca (CIRSA $237=H E p O L$ 24247), Cistierna (AE 1976, $306=$ HEpOL 6584), Segovia (CIL II $5780=$ HEp 4, 1994, $620=H E p O L$ 12086) y en varios lugares de la provincia de Burgos e incluso en Alcalá de Henares (Madrid). Existen otros 14 ejemplos en su forma Ambatus y otros 33 en genitivo. (Ambatif.)

Tipología: IV C

Datación: Por la ausencia de fórmula funeraria se podría datar en el siglo I.

Bibliografía: Inédita

VR-03 Cabecera de estela (Fig. III) Ubicación actual: En casa llamada "Los Arcos", propiedad de J. Manuel "Manolo" Magarzo Pintado y M. N. Blanco Alfonso, en la c/Verónica 4. En una plataforma construida ex profeso para mostrar la pieza, contra la tapia del patio lateral.

Procedencia: Sin especificar, aunque se encontró en las ruinas de la casa existente previamente en la misma finca. Posiblemente del castro de San Mamede.

Dimensiones y material: (42) x 31 $\mathrm{x} 15 \mathrm{~cm}$. Granito blanco, poroso y muy deteriorado, con una textura

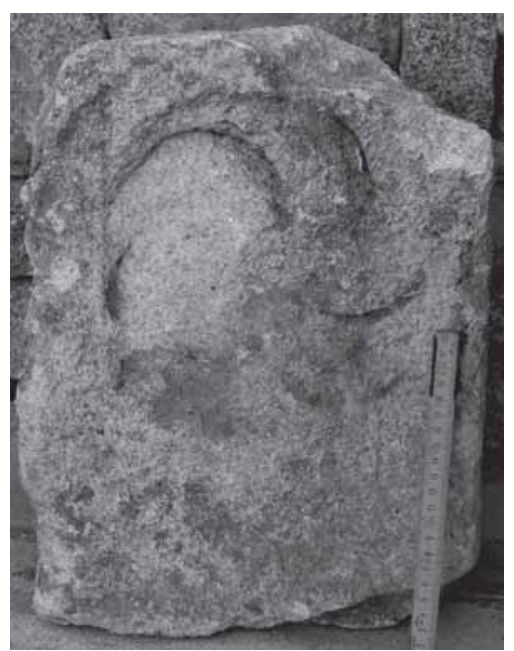

FIG. III similar al azúcar. 


\section{Morfología:}

Cabecera: Rueda de $12 \mathrm{~cm}$ de radio con 7 radios dextrógiros, enmarcada en una suave moldura en bajorrelieve. Muestra una rotura evidente en la esquina superior izquierda.

Cuerpo: No conserva restos de letras. Rotura irregular en el lado izquierdo, aunque no ha dañado prácticamente la pieza. La cara es lisa, salvo por un aparente rebaje que se atestigua en el lado derecho.

Pie: El pie ha desaparecido, no es posible saber lo que falta, aunque se puede aventurar un mínimo de $30 \mathrm{~cm}$ por la proporción de la rueda.

Tipología: IV C

Bibliografía: Inédita

\section{VR-04 Estela funeraria (Fig. IV)}

Ubicación actual: En casa llamada "Los Arcos", propiedad de J. Manuel "Manolo" Magarzo Pintado y M. N. Blanco Alfonso, en la c/Verónica 4. En una plataforma construida ex profeso para mostrar la pieza, contra la tapia del patio lateral.

Procedencia: Sin especificar, aunque se encontró en las ruinas de la casa existente previamente en la misma finca. Posiblemente del castro de San Mamede.

Dimensiones y material: (50) x 35 x $14 \mathrm{~cm}$. Campo epigráfico (14) x $20 \mathrm{~cm}$. Altura de las letras $6 \mathrm{~cm}$.

\section{Morfología:}

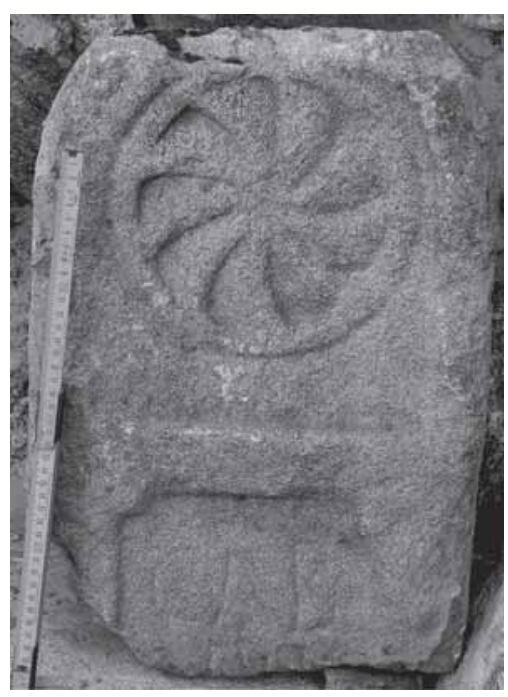

FIG. IV

Cabecera: Rueda y moldura en bajorrelieve, con un radio de $8 \mathrm{~cm}$, y 9 rayos dextrógiros. Presenta una rotura horizontal en la parte superior, que apenas ha afectado la pieza. El conjunto de la cabecera se encuentra enmarcado por una moldura en relieve.

Cuerpo: La cartela se enmarca en unas columnas en relieve, con remarques en las esquinas. La columna del lado derecho se intuye por la destrucción superficial de la pieza, destrucción que no afecta al campo. 
Sin embargo, la pieza se encuentra rota horizontalmente por abajo, dificultando la lectura de la segunda línea.

Pie: Perdido por la rotura anteriormente mencionada.

Transcripción y desarrollo: Cab/uro $/^{3}$ - . . . -

Interpretación: Caburo...

Comentario: Llama la atención lo reducido del campo epigráfico respecto a las dimensiones de la pieza y al gran tamaño de su letras que no permite más de 3 por línea. Es de suponer la falta de al menos una tercera línea con la edad del difunto. Los antropónimos que comienzan con Cabur- son muy habituales en la Península, con unos 23 casos. Un ejemplo cercano lo tenemos con Caburiae en Villalcampo (AE 1992, $1005=H E p$ 5, $901=$ HEpOL 7250) o Caburio en Astorga (CIL II 5666 $=H E p O L$ 11992)

Tipología: I B 1

Datación: Por la ausencia de fórmula funeraria se puede datar en el siglo I ó II d.C.

Bibliografía: Inédito

VR-05 Cabecera de estela (Fig. V) Ubicación actual: Embutido en la pared del salón de la Posada Real $L a$ Mula de los Arribes de Villardiegua, en la calle Verónica número 8 . Se encuentra justo encima de la $\mathrm{n}^{\circ} 6$ de este catálogo.

Procedencia: No especificada.

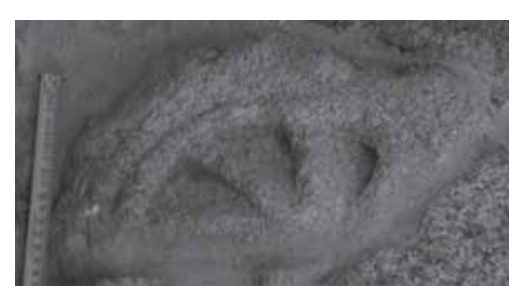

FIG. V

Posiblemente del castro de San Mamede.

Dimensiones y material: (19) x 35 x ? cm. Granito anaranjado.

Morfología:

Cabecera: rueda con moldura en relieve, de $10 \mathrm{~cm}$ de radio, en el que se ven 3

radios dextrógiros de 10-12 (aprox.). Se encuentra roto por todos lados menos por la parte superior izquierda.

Tipología: I ó II

Bibliografía: Inédita 


\section{VR-06 Estela funeraria (Fig. VI y VII)}

Ubicación actual: Embutido en la pared del salón de la Posada Real $L a$ Mula de los Arribes de Villardiegua, en la calle Verónica número 8 . Se encuentra justo debajo de la $\mathrm{n}^{\mathrm{o}} 5$ de este catálogo.

Procedencia: No especificada. Posiblemente del castro de San Mamede.

Dimensiones y material: (45) x 31 $\mathrm{x}$ ? $\mathrm{cm}$. Campo epigráfico (27) $\mathrm{x}$ $20 \mathrm{~cm}$. Altura de las letras $5-8,5 \mathrm{~cm}$.

\section{Morfología:}

Cuerpo: cartela encuadrada en

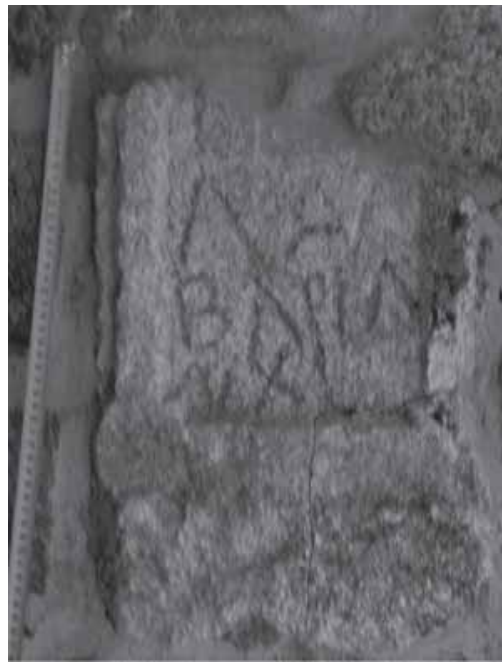

FIG. VII columnas en relieve, pero con el lado derecho parcialmente destruido. Roturas afectando al campo epigráfico en la parte superior derecha, posiblemente en tan solo una línea. El pie de la cartela se apoya sobre una franja lisa.

Pie: sin tratamiento, pero conservado en su integridad aparentemente. Transcripción y desarrollo: --- / le [..]/a Âm/batia/ª̂n(norum) XL Interpretación: ...LE...A AMBATIA, de 40 años.

Comentario: La A no presentan trazo horizontal, excepto en el nexo AM. Ambatia es un nombre habitual en su forma Ambata, con al menos 17 ejemplos conocidos en la Península, especialmente en la provincia de Burgos en lugares como Lara de los Infantes o Belorado.

Tipología: I D

Bibliografía: Inédito

\section{VR07 Estela funeraria (Fig. VIII)}

Ubicación actual: En la pared externa de la casa de los hijos de D. Antonio Pintado, embutida en los muros de la casa en 1960.

Procedencia: San Mamede.

Dimensiones y material: (83) x 39 x ? cm. Campo epigráfico ¿ $37 ?$ X $28 \mathrm{~cm}$. Altura letras $5-4 \mathrm{~cm}$. Granito beige claro. 


\section{Morfología:}

Cabecera: semicircular que presenta un disco en relieve rodeado por una moldura. Los seis radios tienen una longitud de 10,5 cms. La pieza aparece enmarcada por una moldura exterior.

Cuerpo: molduras exteriores en forma de columnas a los lados. No presenta borde inferior al final del texto.

Pie: indeterminado, parece haber una rotura horizontal que no ha afectado a la pieza en general.

Transcripción y desarrollo: Virono/ Turoni $/{ }^{3}$ f(ilio) an (norum) $L X$

Interpretación: A Virono, hijo de Turón, de 60 años.

Variantes: ninguna

Comentario: Virono es un nombre

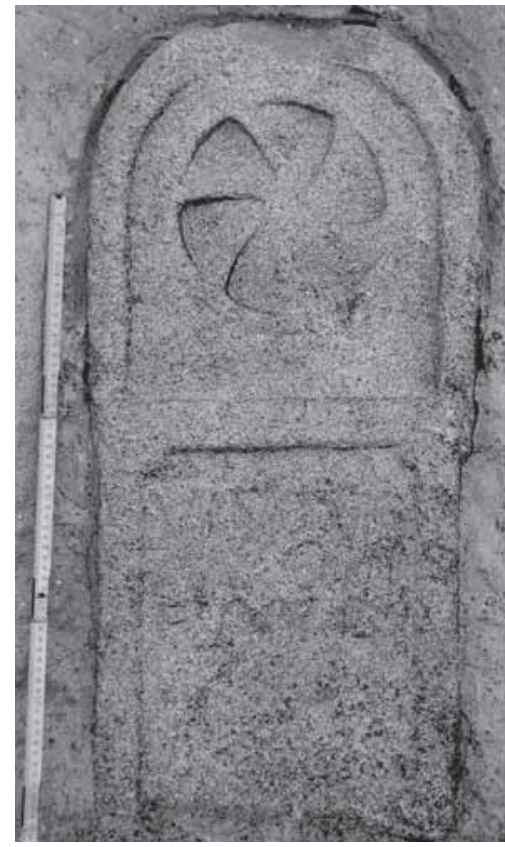

FIG. VIII

habitual en la zona, teniendo más ejemplos en la propia localidad, y en otras zonas como Bragança ( $A E$ 1987, 654 $=$ aEpOL 6947), La Rioja $(A E$ 1976, $330=H E p O L$ 14636), Ávila $(H E p$ 4, $84=H E p$ 9, $79=H E p O L$ 6947) o León (CIL II $5713=$ HEPOL 6947), y en su forma Vironis cuenta con dos ejemplos en Miranda do Douro $(A E$ 1987, $572=H E p$ 3, $454=H E p$ 8, $586=H E p O L 6951$ y $A E$ 1987, $577=H E p$ 3, $438=H E p$ 8, $585=H E p O L$ 15388) . Por su parte, Turono tan sólo hay un caso conocido en Bragança (CIL II 2504 = HEpOL 8331), siendo mucho más habitual el antropónimo Caturono, del que quizá derive y muy usual en la zona portuguesa. Otras derivación posible es el caso de Turaius, localizado en dos inscripciones de Villalcampo (Bragado, $\mathrm{n}^{\circ} 32$ y 58) y una de Rabanales (Bragado, ${ }^{\circ} 90$ ) o Turenius en Castelo Branco (HEp 12,869) y Turenia en Olleros de Pisuerga, Palencia (HEp 12, 501). En cuanto a la decoración, esta estela además de contar con el característico disco en la cabecera, presenta el característico campo epigráfico enmarcado por columnas.

Tipología: I B 1 
Datación: por la ausencia de fórmula funeraria se puede datar en el siglo I ó II d.C.

Bibliografía: BlANCO, 1984, p. 22, nota 49; HEp 5, 908; BRAGADO 1996, p. 24, $\mathrm{n}^{\circ}$ 12, foto 15; HEp 6, 997 (identificada con otra inscripción por error); CIRPZA 317; SiLVA, A. C. F., 2003, p. 49, nº 37; HEpOL 16109

\section{VR-08 Estela funeraria (Fig. IX)}

Ubicación actual: En la casa de Santiago Pintado Velasco, Ermelinda Magarzo de Pintado y María Calvo Prieto, en la c/Sestil 38. Está en posición invertida.

Procedencia: No especificada.

Dimensiones y material: (38) $\mathrm{x}$ $(20,5) \mathrm{x}$ ?cm. Campo epigráfico $(15)$ $\mathrm{x}(15) \mathrm{cm}$. Altura de las letras 5$4,5 \mathrm{~cm}$. Granito beige claro.

\section{Morfología:}

Cabecera: tan solo se conserva la esquina inferior derecha, con una doble moldura enmarcando la cabecera. En el interior hay una escuadra en bajorrelieve, y el extremo de su reflejo en el lado

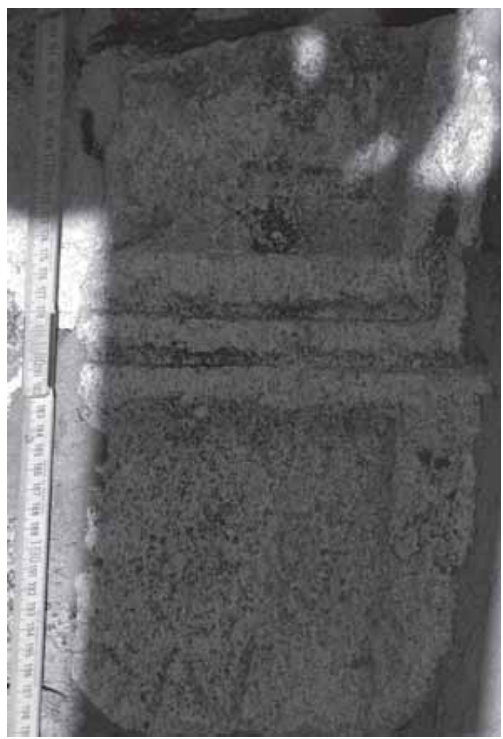

Fig. IX contrario. No se observan restos de rueda, pero es muy probable su existencia.

Cuerpo: se conserva la esquina superior derecha, con una moldura gruesa. Tan sólo mantiene un campo epigráfico reducido. A juzgar por la decoración de escuadras de la cabecera, se podría estimar que faltan unos $11,5 \mathrm{~cm}$ de ancho, 8 de los cuales corresponderían al campo epigráfico (2-3 letras).

Transcripción y desarrollo: [- - ]ovie/[- - ]Cae/3[n] on $[i s] /$. . - Variantes: [D]OVITE/[NAE] CAE $/{ }^{3}[\mathrm{SI} F(\mathrm{LIAE}) \hat{A N}(\mathrm{NORUM}) \mathrm{L}$. Bragado Toranzo.

Comentario: Por el tamaño se puede pensar en la ausencia de 1 ó 2 letras en cada línea antes del texto conservado. La lectura dada por el 
editor anterior no parece probable por varias razones. En primer lugar en lín. 1 la $T$ no existe ya que se trata claramente de una $I$ de menor tamaño. En lín. 3 omite la los restos visibles de la $O$. Tampoco es visible la edad $(L)$ del difunto. No se aprecia el nexo $A N$, y quizá la $\mathrm{O}$ final corresponda a un antropónimo como Caeno, con unos 30 casos en la península, en este caso en genitivo, ya que quizá se avisten los restos de la $I$ y la $S$ al final de la línea. Este nombre cuenta con un caso cercano en Carbajales de Alba $(A E 1977,491)$ y uno posible en San Pedro de la Nave $(A E$ 1941, 18).

Tipología: II B 1

Datación: Por la similitud con otras piezas datadas, se le puede atribuir una cronología de los siglos I y principios del II d.C.

Bibliografía: BragADO, 1991, no 125, lám. LXXXIV, 2; Bragado, 1996, p. 26-27, $\mathrm{n}^{\circ}$ 15, foto 18; HEp 7, 1088; CIRPZA 317; HEpOL 16886; CABaller, $2007 \mathrm{n}^{\circ} 136$

\section{VR-09 Estela funeraria (Fig. $X$ )}

Ubicación actual: Formando el dintel superior de una ventana en una casa, a unos 2,5m sobre la c/ Valdelasheras. Procedencia: No especificada.

Dimensiones y material: (49) x $28 \mathrm{x}$ $11 \mathrm{~cm}$. Altura de las letras $7-6 \mathrm{~cm}$. Granito claro muy deteriorado y poroso.

\section{Morfología:}

Cuerpo: hay indicios de que hubiese una moldura en relieve, picada para nivelar con el resto del campo epigráfico para formar el dintel. La pieza ha sido acondicionada, acortando la pieza por el lado derecho, quizá faltando una letra por ello, aunque la coherencia del texto parece indicar lo contrario.

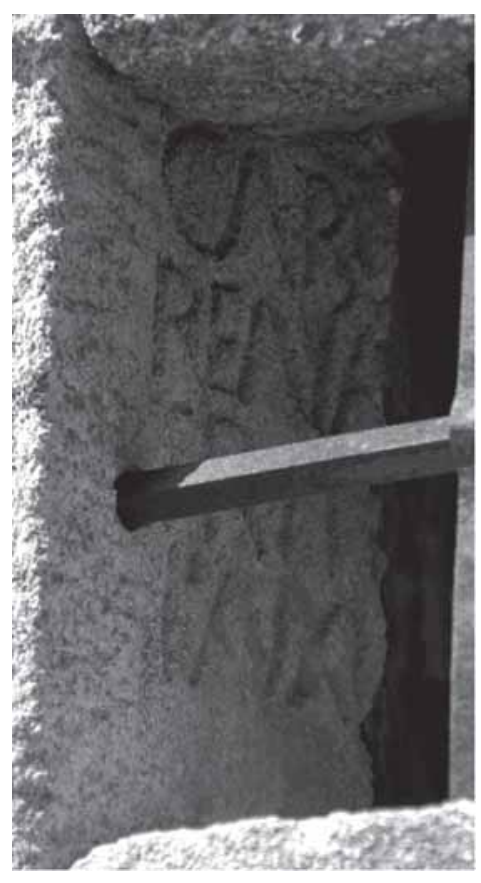

FIG. X 
Pie: por debajo del campo epigráfico hay un orificio centrado, quizá posterior para insertar barrotes como los que hay actualmente perforando parte de la línea 3.

Transcripción y desarrollo: Cabu/rena $/{ }^{3}$ Triti / f(ilia) ân(norum) X[Ló I]. Interpretación: Caburena, hija de Tritio, de 40 (u 11) años.

Comentario: Existe otra Caburena en Coria $(H E p ~ 4,1994,232=H E p O L$ 23052). Tritio aparece, en sus diferentes variantes tanto en masculino como en femenino, unas 33 veces en la Península, y en zonas de la propia provincia de Zamora como Villalcampo $(A E$ 1992, $1006=H E p O L$ 7251 y $A E 1992,1009=H E p O L$ 7253) o en el cercano distrito portugués de Bragança $(H E p$ 12, 2002, $604=$ AE 2002, $772=H E p O L$ 2749; HEp 2, 1990, $766=$ HEp 12, 2002, 585 = HEpOL 22940 ó HEp 2, 1990, 767 = HEpOL 22491; HEp 12, 2002, $579=$ HEpOL 24695 y HEp 12, 2002, $586=H E p O L$ 24699).

Este antropónimo es especialmente abundante en la provincia de Salamanca.

Bibliografía: Inédito

\section{VR-10 Estela funeraria (Fig. XI)}

Ubicación actual: En la el patio de entrada de la casa propiedad de Martín y Dolores, c/Valdelasheras 11.

Procedencia: No especificada. Posiblemente del castro de San Mamede Dimensiones y material: (51) $\mathrm{x}(22) \mathrm{x}$ $14 \mathrm{~cm}$. Campo epigráfico $(9) \times(20) \mathrm{cm}$. Altura de las letras $6 \mathrm{~cm}$. Granito blanco muy poroso.

\section{Morfología:}

Cabecera: el lateral derecho de la inscripción ha desaparecido, seguramente por su uso como sillar. Se observan indicios de una moldura rodeando una rueda de 6 radios dextrógiros de $11 \mathrm{~cm}$ de radio, en relieve.

Cuerpo: la cara está muy deteriorada, pero se observan molduras en forma de cartela

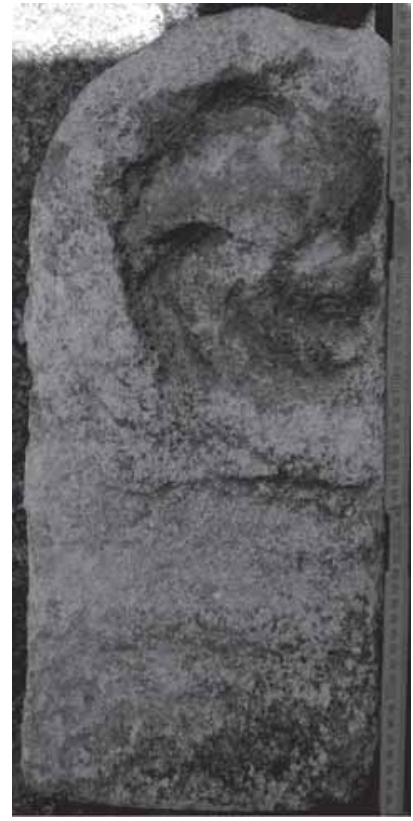

FIG. XI 
de pequeño tamaño bajo el disco. Apenas se observan indicios de letras en el campo epigráfico.

Pie: perdido debido a la adecuación de la pieza como sillar.

Transcripción y desarrollo: $C a$ [-c. 2-3-] / - - . - -

Comentario: Podría ser el inicio de un antropónimo como Caburo o similar.

Bibliografía: Inédito

\section{VR-11 Estela funeraria anepígrafa (Fig. XII)}

Ubicación actual: En la el patio de entrada de la casa propiedad de Martín y Dolores, c/ Valdelasheras 11.

Procedencia: No especificada.

Dimensiones y material: (68) x $33 \times 10 \mathrm{~cm}$. Campo epigráfico $22 \times 11 \mathrm{~cm}$. Tiende a estrecharse en la parte inferior. Granito anaranjado.

\section{Morfología:}

Cabecera: estela bísoma con dos cabeceras con discos en bajorrelieve, de 9 y 7 radios levemente sinistrógiros, de $8 \mathrm{~cm}$ de radio. Cuerpo: dos cartelas en bajorrelieve, sin restos aparentes de escritura.

Pie: liso y más estrecho que la cabeza.

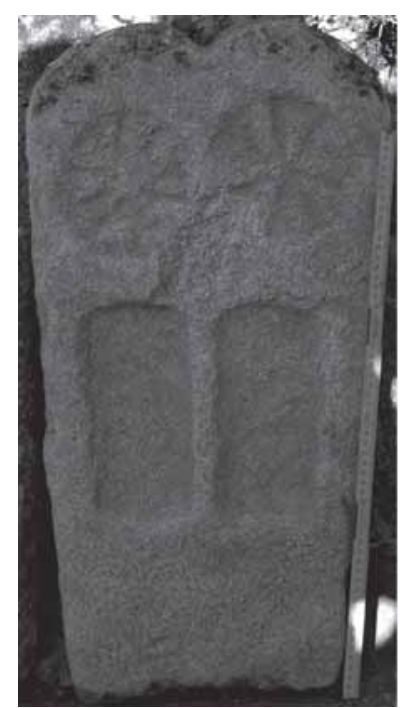

FIG. XII

Comentario: Es posible que la estela fuera anepígrafa desde su origen, aunque su estado erosionado no permite asegurar que nunca contuviera letras. Este tipo de estelas con varios campos epigráficos tiene paralelos en la zona como en Pino del Oro (CIL II 2616 = HEpOL 8427).

Tipología: IV

Bibliografía: Inédito 


\section{VR-12 Estela funeraria (Fig. XIII)}

Ubicación actual: En el corral de una casa semi-abandonada, junto a una plaza, antiguamente perteneciente a Don Manuel Tejado y actualmente propiedad de propiedad de Martín y Dolores.

Procedencia: No especificada.

Dimensiones y material: (82) x $42 \times 13 \mathrm{~cm}$. Campo epigráfico (32) x $22 \mathrm{~cm}$. Altura de las letras $5-4,5 \mathrm{~cm}$. Granito gris.

\section{Morfología:}

Cabecera: rueda con 12 radios dextrógiros de $10,5 \mathrm{~cm}$ de radio, en relieve con moldura rodeándolo y con umbo central. Cabecera aproximadamente escuadrada.

Cuerpo: no es imposible que hubiese una moldura a los lados, actualmente picada.

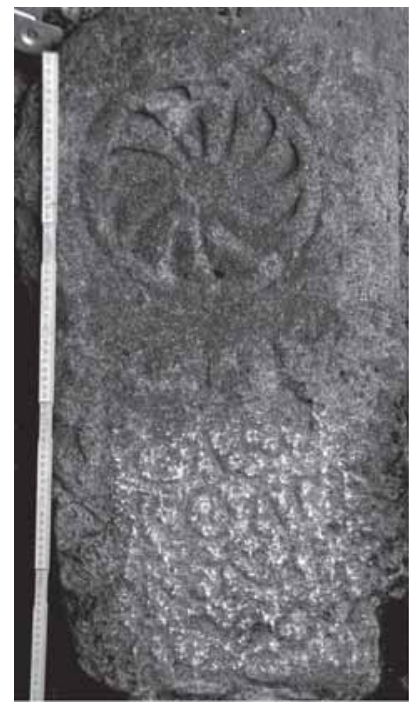

FIG. XIII

Hay una rotura horizontal que posiblemente afecte al campo epigráfico. Pie perdido.

Transcripción y desarrollo: Cabu/ro Ar/ ${ }^{3}$ reniffilio) / a [n] no (rum) / . . - . - -

Variantes: Ar/renti f(ilio), BRAGADO 1991, nº 129; Catu/ro Ar/3reni f(ilio) - / an(norum) XXXI. (HEp 5); XXX[- - -]. CABALLER 2007.

Interpretación: Para Caburo, hijo de Arreni, de ¿?años.

Comentario: La edad propuesta por los editores anteriores no parece probable, ya que la $O$ de annorum es muy clara, así como los restos de la $A$ y de una de las $N$. Se presupone una última línea con un numeral que marcara la edad.

\section{Tipología: I C}

Datación: Por la ausencia de dedicación inicial se podría datar en el siglo I.

Bibliografía: Benito del Rey et AL. 1987, p. 48-50, nº 2, fig. 8; Bragado 1996, p. 244, no 120, lám. LXX, 2 y LXXI, 1; HEp 5, 907; BraGado 1996, p. 20-22, nº 10, foto 12 y 13; HEp 7, 1090; CIRPZa 311; CABALLER 2007, n $135 ;$ HEPOL 16108. 
VR-13 Estela funeraria (Fig. XIV) Ubicación actual: En el corral de una casa semi-abandonada, junto a una plaza, antiguamente perteneciente a Don Manuel Tejado y actualmente propiedad de Martín y Dolores. Se encuentra colocada sobre la $\mathrm{n}^{\circ} 12$ de este catálogo.

Procedencia: No especificada. Posiblemente del castro de San Mamede.

Dimensiones y material: $(66)$ x 54 x $22 \mathrm{~cm}$. Campo epigráfico (26) x

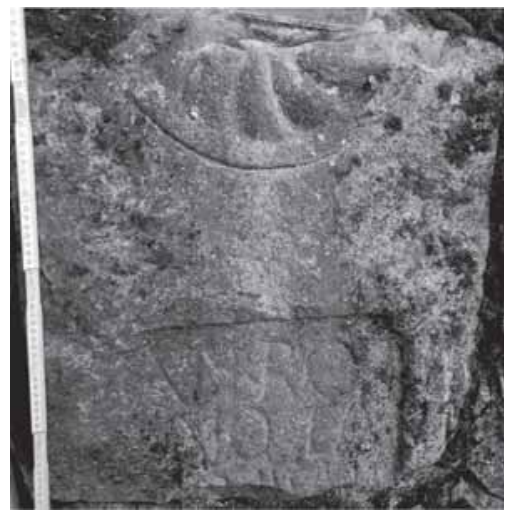

FIG. XIV $34 \mathrm{~cm}$. Altura de las letras $8-7 \mathrm{~cm}$. Granito gris.

\section{Morfología:}

Cabecera: cortada horizontalmente, afectando a la rueda. Ésta tiene 4 rayos dextrógiros (de unos 20 en total aproximadamente) de $11 \mathrm{~cm}$ de radio.

Cuerpo: la cartela se encuentra centrada en bajorrelieve, enmarcada por columnas. Hay una rotura irregular que afecta a la $3^{\mathrm{a}}$ línea del texto. FIG. XIV

Transcripción y desarrollo: Viro/no La $\left.\right|^{3}[.$.$\left.] yif filio \right)+++$ / - -

Interpretación: A Virono, ¿hijo de La[--]vi,....

Variantes: VIRO/NO. Benito del Rey et alii. y HEp 5.; VIRO/NO TA/3 [- - -F(ILIO)- - -]. BRAGADO y CIRPZa.

Comentario: las lecturas dadas por los editores anteriores no son posibles por varias razones. En primer lugar es evidente que existen más letras que las del antropónimo Virono, así mismo la letra $L$ de lín. 2 es clara, así como los restos de la $V$ y la $F$ ó $E$. Es más factible la $F$ como sigla de $F$ (ilius), ya que los restos de letras anterior bien pudiera ser una $I$, indicando un genitivo.

Tipología: I D

Datación: Por la ausencia de dedicación podría datarse en el siglo I d.C.

Bibliografía: Benito del Rey et al. 1987, p. 50, nº 3, fig. 8; HEp 5, 908; Bragado 1996, p. 20-22, nº 10, foto 12 y 13; HEp 6, 997; CIRPZa 318 
VR-14 Estela funeraria (Fig. XV)

Ubicación actual: En el patio de la casa de Estefanía Eras Pablo, empotrado en la pared del pajar.

Procedencia: De las terrazas al pie del castro de San Mamede, traída en los años 20.

Dimensiones y material: (88) x $50 \mathrm{~cm}$. Campo epigráfico $(31) \times 37 \mathrm{~cm}$. Altura de las letras $6,5-6 \mathrm{~cm}$. Granito gris.

\section{Morfología:}

Cabecera: una moldura exterior abarca toda la cabecera. Rueda con 13 rayos dextrógiros de $15 \mathrm{~cm}$ de radio.

Cuerpo: El campo epigráfico está enmarcado por columnas y fragmentado. Transcripción y desarrollo: Totono / Arconis $/{ }^{3}$ an (norum) $L$

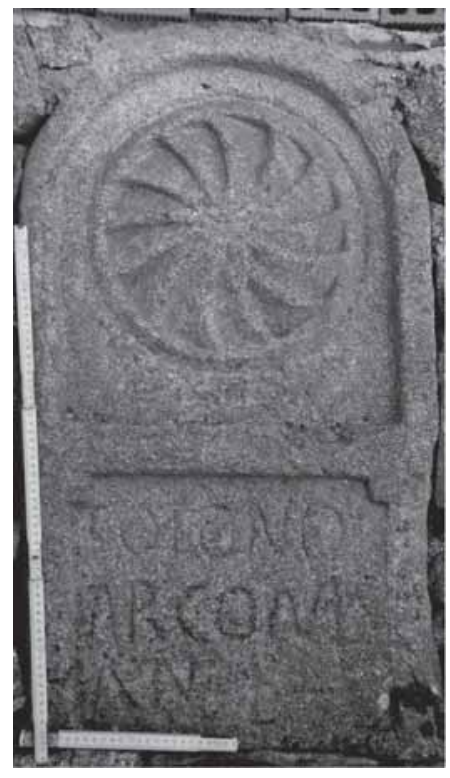

FIG. XV

Interpretación: Para Totono, hijo de Arco, de 50 años.

Comentario: Totono constituye casi un hapax en Hispania en esta variante (si bien existe un posible caso en genitivo en Chillón, Ciudad Real), no así en su forma Toutono, ya que tenemos tres ejemplos en la localidad vecina de Villalcampo (Bragado, 1991, n 31, 42 y 54). Es llamativa la ausencia de la letra $f$ para marcar la filiación. Arconis por su parte, es muy frecuente en toda la

Península Ibérica, teniendo incluso varios ejemplos en la propia provincia de Zamora como en Carbajales de Alba $(A E$ 1977, $491=$ HEpOL 6639), Villalazán $(C I R P Z a 221=H E p$ 5, 1995, $895=H E p 10$, 2000, $632=H E p O L$ 14045) y el no 19 de este catálogo.

Tipología: I B 1

Datación: Por la ausencia de fórmula funeraria y de la abreviatura de filiación se puede datar en el siglo I d.C.

Bibliografía: Benito del Rey et AL. 1987, p. 50, no 4, fig. 9; HEp 5, 909; BRAGADO 1996, p. 25-26, no 13, foto 16 y 17; HEp 6, 997; CIRPZa 316; HEpOL 16110; CABALLER 2007, $\mathrm{n}^{\circ} 137$. 


\section{VR-15 Estela anepígrafa (Fig. XVI)}

Ubicación actual: En el patio de la casa de Estefanía Eras Pablo, empotrado en la pared del pajar.

Procedencia: De las terrazas al pie de San Mamede, traída en los años 20.

Dimensiones y material: (72) x $47 \mathrm{~cm}$. Granito entre blanco y gris claro.

\section{Morfología:}

Cabecera: un arco en bajorrelieve que rodea lo que podría haber sido una rueda y, debajo, un par de escuadras. La dueña afirma que había una "cara muy fea" y que por ello la picó.

Cuerpo: la zona correspondiente al

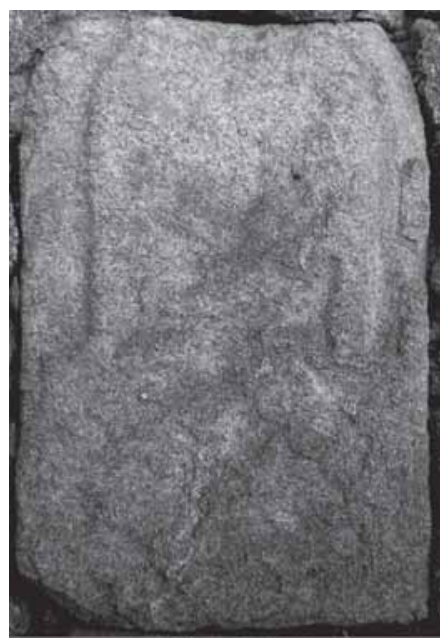

FIG. XVI campo epigráfico parece ocupada por una malla de rombos. Por ello, es imposible distinguir cuerpo de pie.

Comentario: Estela funeraria posiblemente con rueda de radios como en las otras estelas de la zona. Lo original de esta estela lo constituiría la presencia de un damero en la zona del campo epigráfico del que sí parece que podrían quedar algunos trazos.

Bibliografía: BRAGADO 1991, no 124, lám. LXXIV, 1; Bragado 1996, p. $26, \mathrm{n}^{\circ} 14$, foto 17 ; $\operatorname{HEp} 7,1089$

\section{VR-16 Cuerpo de estela (Fig. XVII)}

Ubicación actual: En la pared externa del pajar que ocupa actualmente el solar de la ermita San Roque.

Procedencia: Indeterminada, se conocía en la ermita San Roque.

Dimensiones y material: (66) x (32) $\mathrm{cm}$. Campo epigráfico (34) x (25) cm. Granito gris.

\section{Morfología:}

Cabecera: pieza muy deteriorada y rota por los lados. Parece haber una moldura, atestiguada en la parte inferior derecha, enmarcando lo que sería una rueda.

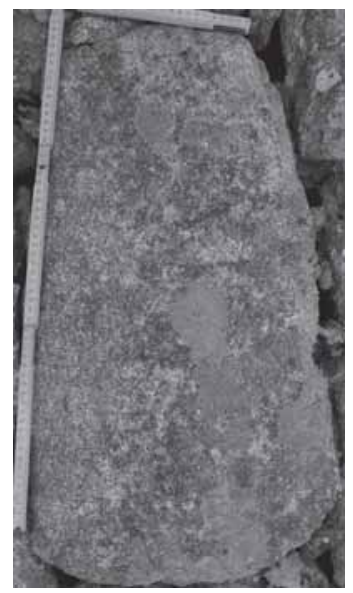

FIG. XVII 
Cuerpo: podría haber una cartela en bajorrelieve de la que sobreviviría el moldurado superior derecha.

Variantes: Velu/a Triti [f(ilia) ${ }^{\beta} /$ an(norum) [- - - ]. Todos los autores Comentario: Pieza muy deteriorada que podría responder a las noticias de que había una inscripción en las ruinas de la ermita allí sita. La pieza ha perdido la forma y está seguramente cortada. No estamos seguros de la identificación de esta pieza.

Bibliografía: Si corresponde a la que mencionan algunas fuentes sería Morán 1944, 245/6, 13; Morán 1946, p.131; Sevillano 1978, p.11, n ${ }^{\circ}$ 198; CIRPZa 310

VR-17 Fragmento de
inscripción (Fig. XVIII)
Ubicación actual: En la pared jalonando la entrada de cocheras del pajar en la c/ Empornada 2, propiedad de Manuel Luengo.

Procedencia: No especificada.

Dimensiones y material: (11) $\mathrm{x}$ (34) $\mathrm{cm}$. Altura de las letras $5 \mathrm{~cm}$.

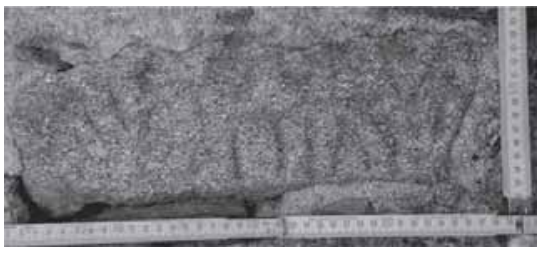

FIG. XVIII Granito gris claro.

\section{Morfología:}

Cuerpo: solo se conserva un fragmento de la pieza seguramente cortado para su uso como sillar. El fragmento conservado corresponde al campo epigráfico. Sin embargo, los renglones no son respetados en la parte izquierda, donde parece haber más letras, aunque no es descartable que sean decoración.

Transcripción y desarrollo: - - . - - [Fl] avio / AT[...] - . . - -

Interpretación: ...Flavio....At...

Variantes: - - - - - / Avili · [- - - ] / an(norum) + + / - _ _ _ - 4

Comentario: Es difícil precisar las lecturas, y sería necesario un calco. Lo más factible parece la opción del antropónimo Flavio, muy frecuente en Hispania. No es descartable tampoco la lectura Avilio o Avilia, y que se trata de un nombre común en la Península, con un ejemplo cercano

\footnotetext{
${ }^{4}$ Lectura propuesta por el Dr. Gómez-Pantoja, a quien agradecemos su amable colaboración.
} 
en Miranda do Douro (HEp 3, $451=A E$ 1987, $569=H E p O L$ 15399), o incluso Favilio, con un caso en Zamarra, en la provincia vecina de Salamanca $(A E 1994,889=H E p$ 5, $680=H E p O L$ 23165). Por su parte $A T$ es el comienzo de varios antropónimos atestiguados en la península Ibérica, por lo que sería aventurado proponer ninguno, más si cabe cuando no estamos seguros de que correspondan al inicio del nombre.

Bibliografía: Inédito

\section{VR-18 Fragmento de estela}

\section{(Fig. XIX)}

Ubicación actual: En el muro externo que mira a un solar lateral de una casa abandonada y parcialmente derruida.

Procedencia: No especificada.

Dimensiones y material: (52) $\mathrm{x}$ $39 \mathrm{~cm}$. Campo epigráfico (6) x $27 \mathrm{~cm}$. Granito gris claro.

\section{Morfología:}

Cabecera: una moldura gruesa exterior enmarca la cabecera que contiene una rueda, también en bajorrelieve, con 11 rayos sinistrógiros de $12 \mathrm{~cm}$ de radio. Dos

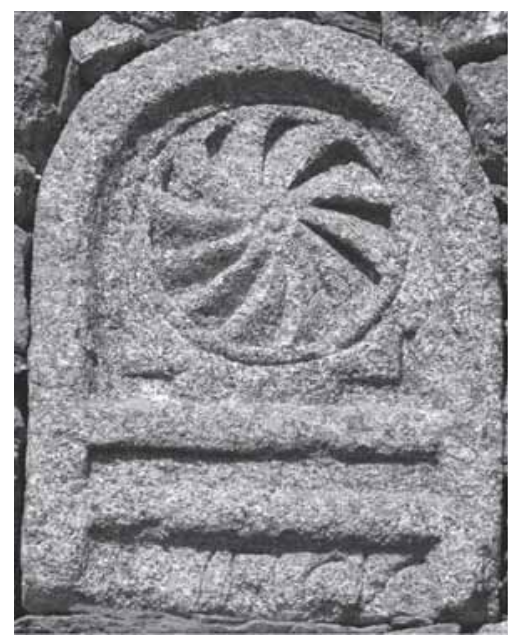

FIG. XIX escuadras bajo la rueda dos escuadras. Franja horizontal rebajada.

Cuerpo: la gruesa moldura exterior en relieve enmarca la cartela rehundida. Un corte en horizontal afecta a la primera línea en parte.

Transcripción y desarrollo: [.]nẹç̣c / - . . - -

Interpretación:

Variantes: Lín. 1[- - - / URCIO, Todos.

Comentario: No existe ningún paralelo en la Península de este supuesto nombre. El mal estado de las letras hace

inviable su interpretación. Sólo hay un ejemplo de un Urciolus en Tarragona (RIT 927a $=$ HEPOL 19815) y un Urceus en un grafito de Logroño (HEp 4, 595a). No nos parece probable la lectura propuesta 
por los editores anteriores, ya que los primeros restos conservados parecen corresponder a una $N$, además de ser más que probable que falte una letra al principio del texto. Por otro lado la $O$ final no es tal, ya que se trata de una media circunferencia, que sólo puede corresponder a una $C$.

Tipología: I ó II

Datación: por el tipo de decoración y la ausencia de dedicación se puede datar en el siglo I ó II d.C.

Bibliografía: MorÁn 1944, 246; Morán 1946, p.131; Sevillano 1978, p.11, n 197; CIRPZa 320

\section{VR-19 Estela funeraria (Fig. XX)}

Ubicación actual: En un muro de un pajar mirando al patio interior de una casa semiderruida. Junto a la $n^{\mathbf{0}} 20$ de este catálogo.

Procedencia: No especificada.

Dimensiones y material: (78) $\mathrm{x}(51)$ cm. Campo epigráfico $30 \times 38$. Altura de las letras $4,5-4 \mathrm{~cm}$. Granito gris-beige.

\section{Morfología:}

Cabecera: posiblemente con rueda de radios, pero no se ha conservado.

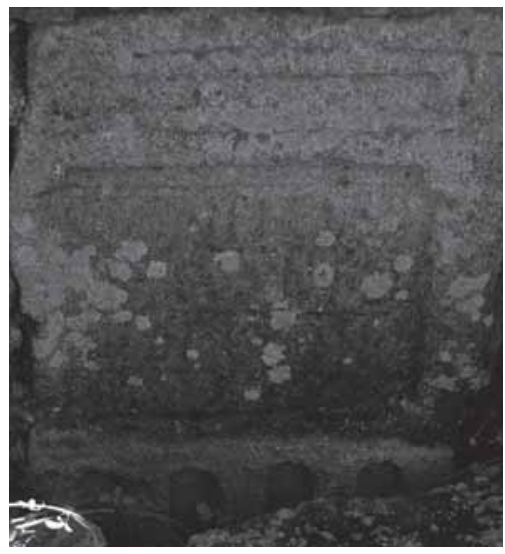

FIG. XX

Hay una doble moldura rodeando una franja horizontal en la parte superior.

Cuerpo: campo epigráfico enmarcado por columnas. Presenta líneasguía que dividen el campo epigráfico en cuatro partes, quedando el último anepígrafo.

Pie: Cuatro arcos de medio punto llegan hasta el final de la pieza.

Transcripción y desarrollo: Cloutio $A /$ rconis $/{ }^{3}$ f(ilio) an(norum) XXVI

Interpretación: Para Cloutio, hijo de Arcón, de 26 años.

Variantes: Lín 2. RCCONIS, Benito del Rey.

Comentario: Cloutio es un nombre muy frecuente en la zona con ejemplos de Alcañices (HEp 7, $1068=$ HEpOL 16871), Rabanales (ILER 2343), Rábano de Aliste (HEp 7, 1079 = HEpOL 16879), Muelas del 
pan $(A E$ 1992, 1011a = HEPOL 7255) y Villalcampo (ILER 2332; HAE 895; HAE 928). En el propio Villardiegua tenemos otro ejemplo (vid. $\mathrm{n}^{\circ}$ 29 de este mismo catálogo). Sobre Arconis vid. inscripción $\mathrm{n}^{\circ} 14$ de este mismo catálogo.

Tipología: II B. La moldura situada sobre la cartela no está incluida en la tipología.

Datación: Por ausencia de fórmula funeraria se podría datar en siglo I. Bibliografía: Benito del Rey et AL. 1987, p. 48, nº 1, fig. 7; HEp 5, 906; CIRPZa 312: HEpOL 16107.

\section{VR-20 Pie de estela (Fig. XXI)}

Ubicación actual: En un muro de un pajar mirando al patio interior de una casa semiderruida. Junto a la $\mathrm{n}^{\mathrm{o}} 19$ de este catálogo.

Procedencia: No especificado.

Dimensiones y material: (63) x 49 $\mathrm{cm}$. Granito beige.

\section{Morfología:}

Dos arcos de medio punto entre columnas (aunque los capiteles de las mismas dan apariencia de arcos de herradura). La pieza es muy alta, y el corte tanto en el borde superior como en las esquinas superiores, en

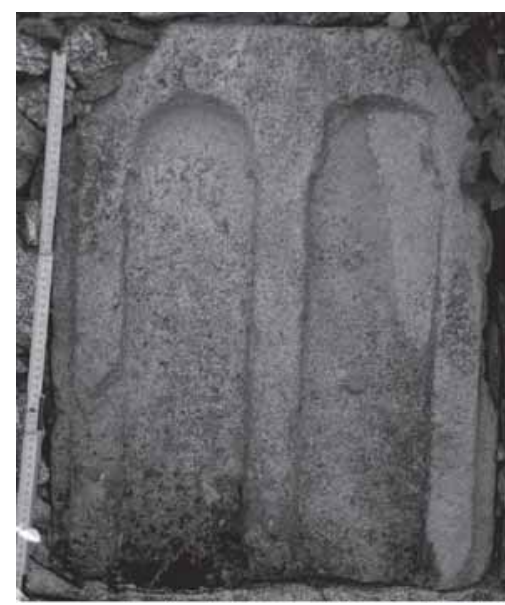

FIG. XXI diagonal, es muy limpio.

Comentario: El tipo de decoración para el pie de las estelas (pie de arquerías) no es raro en la zona, aunque llama la atención el gran tamaño de este pie, lo que hace suponer que pertenecería a una gran inscripción como otras del mismo lugar (vid. $\left.\mathrm{n}^{\mathrm{o}} 25\right)$.

Tipología: II

Bibliografía: Inédito 


\section{VR-21 Fragmento de estela} (Fig. XXII)

Ubicación actual: En el Museo de Villardiegua, con el número de inventario VRA26.

Procedencia: No especificada, posiblemente del castro de San Mamede. Dimensiones y material: (38) $\mathrm{x}(15) \mathrm{x}$ $13 \mathrm{~cm}$. Campo epigráfico $(6,5) \times(9) \mathrm{cm}$. Altura de las letras $(3,5) \mathrm{cm}$. Granito beige claro.

\section{Morfología:}

Cabecera: la pieza presenta roturas importantes en el lado izquierdo y el borde superior. Esto no impide ver una moldura gruesa rodeando la cabecera, dentro de la cual hay un disco en bajorrelieve con 3 de 7 (aprox.) rayos

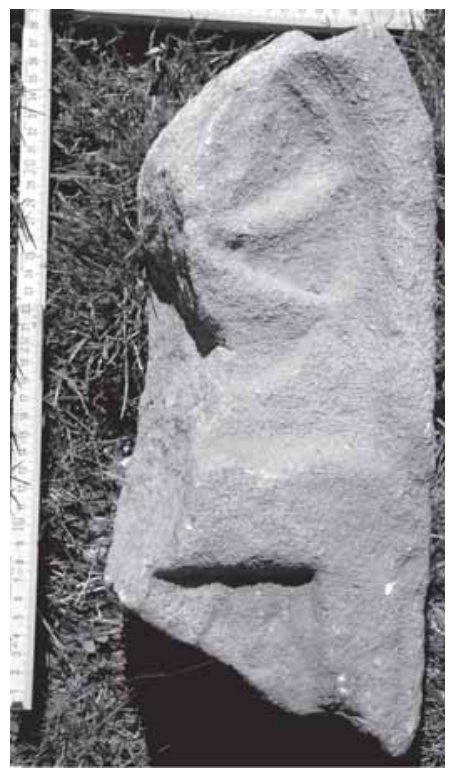

FIG. XXII dextrógiros de $8,5 \mathrm{~cm}$ de radio.

Cuerpo: tan solo se conserva la esquina superior derecha del cuerpo, donde se conserva la presencia de columnas en relieve laterales.

Pie

Perdido.

Transcripción y desarrollo: - - - - - / [- - - ]M/ - - - - -

Comentario: El mal estado de la pieza no permite ninguna reconstrucción

\section{Tipología: I}

Bibliografía: Inédito 
VR-22 Fragmento de estela (Fig. XXIII)

Ubicación actual: En el Museo de Villardiegua, con el número de inventario VRA19.

Procedencia: No especificada.

Dimensiones y material: (50) x 23 x $15 \mathrm{~cm}$. Granito entre gris y beige claro.

\section{Morfología:}

Cabecera: semicircular aparentemente sin rueda ni molduras. Únicamente una luna creciente y dos escuadras aparentemente unidas por la base.

Cuerpo: el mal estado de la pieza hace imposible determinar el comienzo del cuerpo, que se encuentra roto en la parte inferior.

Bibliografía: Inédito

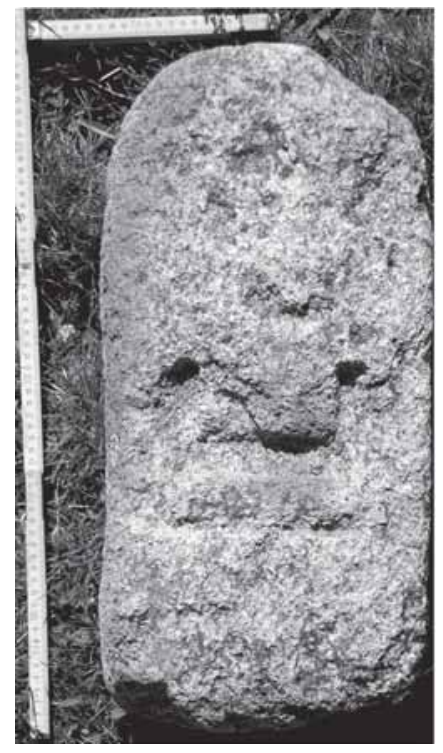

FIG. XXIII

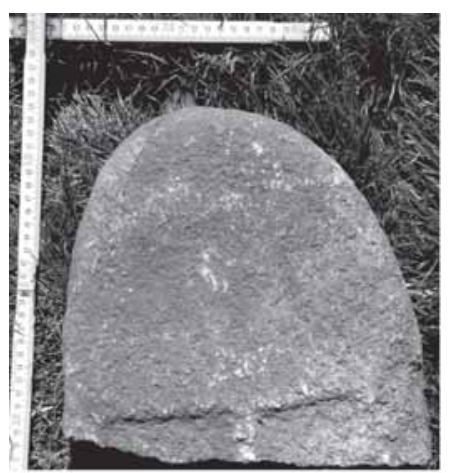

FIG. XXIV

\section{VR-23 Fragmento de estela} (Fig. XXIV)

Ubicación actual: En el Museo de Villardiegua, con el número de inventario VRA25.

Procedencia: No especificada.

Dimensiones y material: $(27) \mathrm{x}(27,5)$ x $6 \mathrm{~cm}$. Campos epigráficos: (5) x $8 \mathrm{~cm}$. Altura de las letras 3 (aproximadamente). Morfología:

Cabecera: arco abierto y una cara bastante alisada, que no presenta indicios de tallado.

Cuerpo: cartela doble, de la que apenas se conserva un poco por la rotura que ha perdido la parte inferior del cuerpo.

Transcripción y desarrollo: a) - - - - - b) an(norum) / - . - . -

\section{Tipología: V}

Datación: Por el tipo de monumento siglos I-II d.C.

Bibliografía: Inédito 


\section{VR-24 Cabecera de estela} (Fig. XV)

Ubicación actual: En la pared externa de una casa, en la carretera de entrada desde Villadepera, $n^{\circ} 1$, antes del desvío hacia la iglesia.

Procedencia: No especificada.

Dimensiones y material: (27) x $46 \mathrm{~cm}$. Granito beige anaranjado claro.

\section{Morfología:}

Cabecera: pieza muy deteriorada y rota por la parte inferior. Solo se

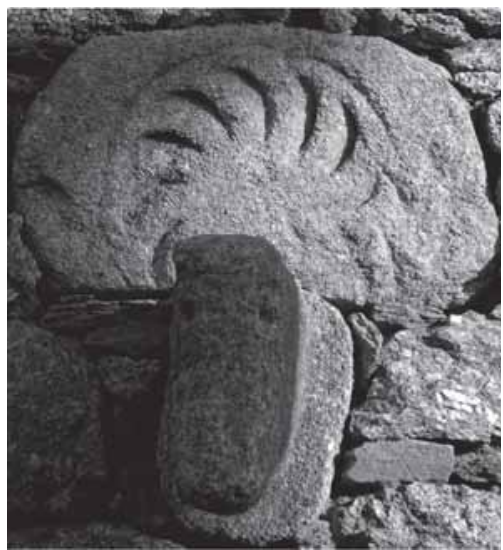

FIG. XXV conserva el disco de $15 \mathrm{~cm}$ de radio en bajorrelieve, con 11 rayos dextrógiros (de 13 en total) conservados. Tipología: IV

Bibliografía: Inédito

VR-25 Estela funeraria (Fig. XXVI) Ubicación actual: Museo de Zamora. Procedencia: No especificada. Posiblemente del castro de san Mamede. Dimensiones y material: $134 \mathrm{x} 42 \mathrm{~cm}$. Letras: 7. Granito beige anaranjado claro. Morfología:

Cabecera: una moldura exterior marcando la cabecera. Dentro de la moldura rueda con umbo con 12 rayos dextrógiros.

Cuerpo: cartela rebajada y enmarcada por columnas.

Pie: hilera de arcos de medio punto entre columnas. La pieza es muy alta y estilizada.

Transcripción y desarrollo: Cudiae/ Arconi $\left.\right|^{3}$ s f(ilia) an (norum) $X$

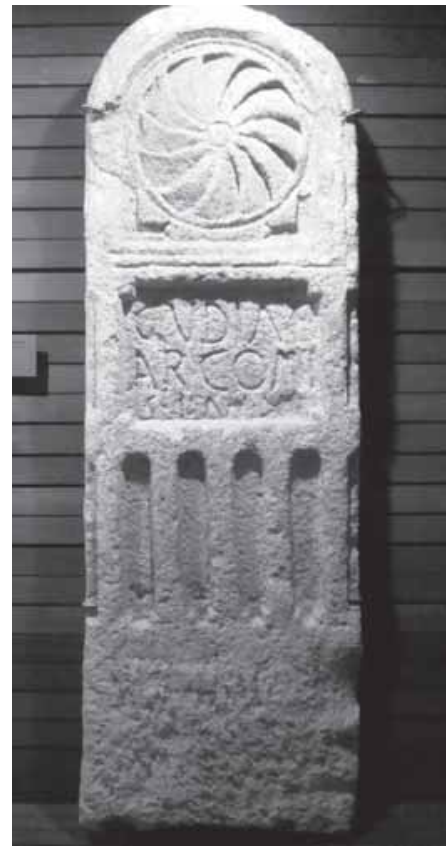

FIG. XXVI 
Interpretación: Cudia, hija de Arcón, de 10 años.

Comentario: Cudia es un hapax en la Península Ibérica, si bien existe una posible Cudia en Saldeana (SA), aunque la lectura es dudosa (HEp 10, $490=A E$ 2000, $703=$ HEpOL 22145). Para el antropónimo Arconis vid. $\mathrm{n}^{\circ} 14$ y 19 de este mismo catálogo.

Tipología: II A

Datación: Por la ausencia de dedicación y fórmula funeraria se puede datar en el siglo I.

Bibliografía: Diego SANTOS, F., 1954, p. 489-490. n 62; HAE 935;

Sevillano, 1978, p.11, no 195; AbÁsolo - García 1990, p. 552, no 34;

AbÁsolo- Marco 1995, p. 332, lám. VIII; CIRPZa 313; CABAller 2007, $\mathrm{n}^{\circ} 81$.

\section{VR-26 Estela funeraria}

Ubicación actual: Estuvo en la casa de Froilán Magarzo (vid. n ${ }^{\circ} 8$ ). Actualmente se encuentra desparecida.

Procedencia: Castro de San Mamede

Dimensiones y material: (91) x 48cm. Letras: 9. Granito blanco y fino, que no existe en la zona, posiblemente traído desde Portugal.

\section{Morfología:}

Cabecera: rueda con 12 radios.

Sólo se conoce que se encontraba incompleta en su parte inferior.

Transcripción y desarrollo: Talao $\cdot D /$ oci $\cdot f($ ilio $) \cdot a n\left(\right.$ norum) $/{ }^{3} \mathrm{LXX}$

Interpretación: Talao, hijo de Docio, de 70 años.

Variantes: TALA · OD/OCI. Morán 1944 y 1946; Sevillano 1978.

Comentario: Parece más probable la primera opción, ya que existen en la Península al menos tres ejemplos del antropónimo Docio, dos en Bragança ( $A E$ 1941, 19= HEpOL 6395 y CIL II 5070= HEpOL 11805) y uno en la propia provincia de Zamora, en San Pedro de la NaveAlmendra (HEp 12, $579=H E p O L$ 24695). Talao no existe como tal en la Península (a excepción quizá de Talai (filia) en San Pedro de la NaveAlmendra, $A E$ 1941, $20=H E p O L$ 6396), pero si es habitual Talavi, con ejemplos en Bragança (HEp 4, $1018=H E p$ 7, $1169==H E p$ 12, $601=$ HEpOL 2743; AE 1989, $433=H E p$ 4, $1019=H E p$ 7, $1170=H E p$ 12, $600=H E p O L ~ 7099 ;$ HEp 2, $762=H E p$ 12, $582=H E p O L 22936$ у HEp $12,610=H E p O L$ 24709) y Villalcampo $(C I R P Z a 280=H E p 10,634=$ HEpOL 14048), así como en varios lugares más de toda la Península. 
Datación: Por la ausencia de dedicación y fórmula funeraria se podría datar en el siglo I.

Bibliografía: Morán 1944, 246, 14; Morán 1946, 131; GARCía MERINO 1975, 429, no 351; SeVILlano 1978, p.11, nº 196; CIRPZa 315

\section{VR-27 Estela funeraria}

Ubicación actual: Museo de Zamora.

Procedencia: ruinas de la ermita de San Mamede, hallada durante las excavaciones de 2001 como parte del proyecto de reconstrucción de la ermita. La estela estaba fragmentada en cuatro partes, faltando la cabecera.

Dimensiones y material: (86) x 39 x 15,5 cm. Letras: 6-4. Granito.

\section{Morfología:}

Cuerpo: campo epigráfico enmarcado entre pilastras rematadas por capitel o zapata decorativa.

Pie: presenta una oquedad cuadrangular producto de su reutilización en la ermita como umbral de puerta, goznera o quicialera.

Transcripción y desarrollo: Ânia / Cada/ ${ }^{3}$ riffilia) ân(norum) $X / X$ Interpretación: Aunia, hija de Cadaro, de 20 años.

Comentario: Aunia es un nombre habitual en la Península, con un ejemplo cercano en Bragança $(H E p$ 12, $604=A E 2002,772=H E p O L$ 2749). Cadaro cuenta también con varios ejemplos en Castilla y León y Extremadura.

Tipología: I D?

Datación: Por el tipo de decoración y la ausencia de dedicación y fórmula funeraria se puede datar en el siglo I-II d.C.

Bibliografía: Martín CARBAJo, M. Á et alii, 2001, 37-38, lám II, 2; HEp 11, 589; HEPOL 24608.

\section{VR-28 Estela funeraria}

Ubicación actual: Museo de Zamora.

Procedencia: ruinas de la ermita de San Mamede, hallada durante las excavaciones de 2001 como parte del proyecto de reconstrucción de la ermita. La estela estaba fragmentada en dos partes, faltando la cabecera y el principio del campo epigráfico.

Dimensiones y material: (53) x 39 x 19,5 cm. Letras: 8-6. Granito. 


\section{Morfología:}

Campo epigráfico enmarcado entre pilastras rematadas por capitel o zapata decorativa.

Pie: presenta un rebaje a bisel producto de su reutilización.

Transcripción y desarrollo: - . . . - / [Ar]roni/s f(ili-) · an(norum) / ${ }^{3} \mathrm{XXX}$

Interpretación: ...hijo/a de Arronio, de 30 años.

Comentario: $\mathrm{F}=$ II. Arronis es un nombre habitual en la Península, con un ejemplo en Fariza, en la misma provincia de Zamora ( $A E$ 1981, $542=H E p O L$ 6688). Los dos trazos verticales en vez de la $F$ no son habituales en la zona.

Tipología. tal vez I D.

Datación: Por la ausencia de dedicación y fórmula funeraria se podría datar en el siglo I.

Bibliografía: MARTín et alii 2001, 37, lám II, 3; HEp 11, 590; HEpOL 24608.

\section{VR-29 Estela funeraria}

Ubicación actual: Desconocida, el testimonio de Gómez Moreno testifica que las llevaron a Villardiegua, pero que a pesar de sus intentos no las volvió a ver.

Procedencia: Castro de San Mamede, el primero de los fragmentos estaba en la ermita, y los otros dos formaban parte de las cercas de los alrededores.

Dimensiones y material: (91) x 48cm. Letras: 9. Granito blanco. Morfología:

Cabecera: estela trísoma con discos solares

Transcripción y desarrollo:a) [- - - / o Clou/ ti f(ilio) an(norum) $/{ }^{3}$ XII

b) [- - ] / Pentili f(ilio) a/n(norum) LXX

c) $\left[--70 /\right.$ Clouti $\left[f(\right.$ ilio) $] /$ an(norum) $/{ }^{3} X X$

Interpretación: .... O, hijo de Cloutio, de 12 años; ...hijo de Pentilo, de 70 años; ...O, hijo de Cloutio, de 20 años.

Comentario: Para el antropónimo Cloutio vid. $\mathrm{n}^{\circ} 19$ de este mismo catálogo. Pentili hay tres ejemplos en la Península, uno en el llamado Pacto de los Zoelas de Astorga CIL II $2633=$ HEpOL 8444, otro en Resende, Viseu $(A E$ 1986, $287=H E p$ 1, $703=H E p O L$ 20516) y otro en Talavera de la Reina, Toledo (CIL II $5335=H E p O L$ 320). 
Datación: Por la ausencia de fórmula funeraria se podría datar en el siglo I.

Bibliografía: Gómez Moreno 1927, 28-29, N 60-62; Sevillano 1978, p. 7 y 10, no 107-109 = 192-194; CIRPZa 319; HEpOL 24851.

\section{VR-30 Cabecera de estela (Fig. XXVII) \\ Ubicación actual: En el Museo de Villardiegua, sin número de inventario por tratarse de un hallazgo reciente. \\ Procedencia: hallada en Peña Culebra.}

Dimensiones y material: (40) $\mathrm{x}(19)$ x $14 \mathrm{~cm}$. Granito beige anaranjado claro.

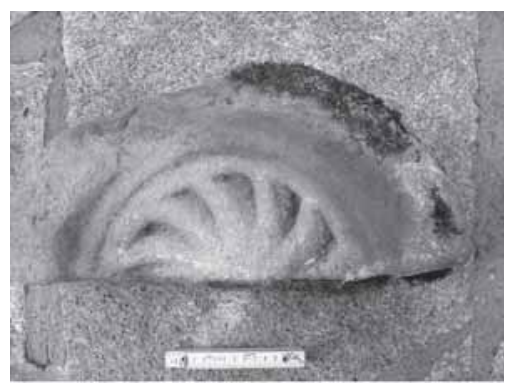

FIG. XXVII

\section{Morfología:}

Cabecera: pieza fragmentada en su parte inferior, y que sólo conserva la parte superior de la rueda, rodeada por una moldura, con 7 radios que giran hacia la izquierda.

Tipología: I ó II

Bibliografía: Inédito

VR-31 Cabecera de estela (Fig. XXVIII)

Ubicación actual: En una casa de Villardiegua, propiedad de don Miguel Bártulo, incrustada en el interior a la izquierda de la puerta de entrada.

Procedencia: probablemente San Mamede.

Dimensiones y material: (29) $\mathrm{x}$ (29) x (?) cm. Granito gris.

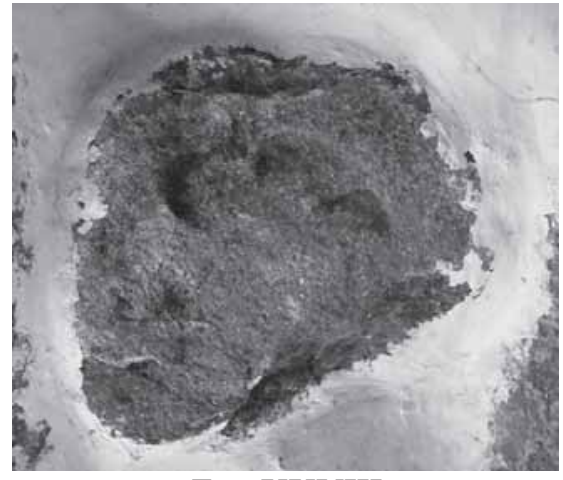

Fig. XXVIII

\section{Morfología:}

Cabecera: la pieza sólo conserva la parte superior de la rueda, con 5 radios que giran hacia la derecha.

Bibliografía: Inédito 
VR-32 Cuerpo de estela (Fig. XXIX)

Ubicación actual: En el museo de Villardiegua, sin número de inventario.

Procedencia: probablemente San Mamede.

Dimensiones y material: (30) $\mathrm{x}(22)$ x $11 \mathrm{~cm}$. Granito gris.

\section{Morfología:}

Posible parte central de una pieza que presenta una cruz central que la divide en cuatro partes.

Datación: La adscripción a época romana de la pieza es dudosa, pudiendo tratarse de un ejemplar de época medieval.

Bibliografía: Inédito

\section{VR-33 Cabecera de estela (Fig. XXX)}

Ubicación actual: En una casa de Villardiegua, incrustada en la pared delantera, a unos 3-4 metros de altura, propiedad de Doña Francisca Plaza. No pudimos acceder directamente a la pieza, lo que limita nuestra autopsia.

Procedencia: desconocida.

Dimensiones y material: (?) $\mathrm{x}($ ?) $\mathrm{x}$ ? $\mathrm{cm}$. Granito gris muy claro.

\section{Morfología:}

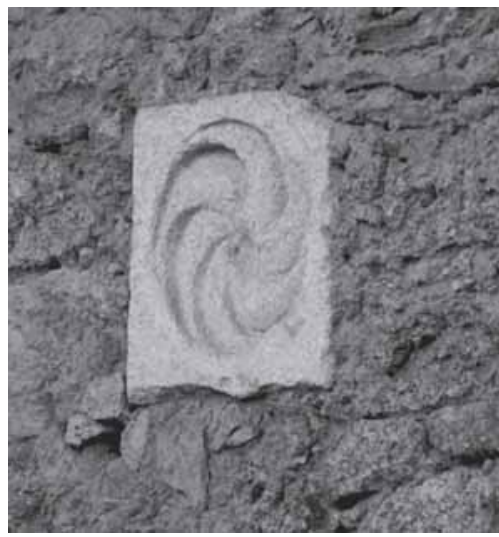

FIG. XXX

Cabecera: se encuentra completa, presentando una rueda con 6 radios que giran hacia la izquierda. A diferencia de todas las estelas documentadas presenta una cabecera cuadrada, lo que nos hace dudar de su autenticidad.

Comentario: por el color y el extraordinario estado de conservación podría tratarse de una copia moderna

Bibliografía: Inédito 


\section{VR-34 Cabecera de estela (Fig. XXXI)}

Ubicación actual: en una casa en ruinas frente a la Posada Real La Mula de los Arribes, que está siendo rehabilitada para ampliar dicho establecimiento. La pieza se encuentra incrustada en la parte NE de la casa.

Procedencia: probablemente San Mamede.

Dimensiones y material: (26) x 10

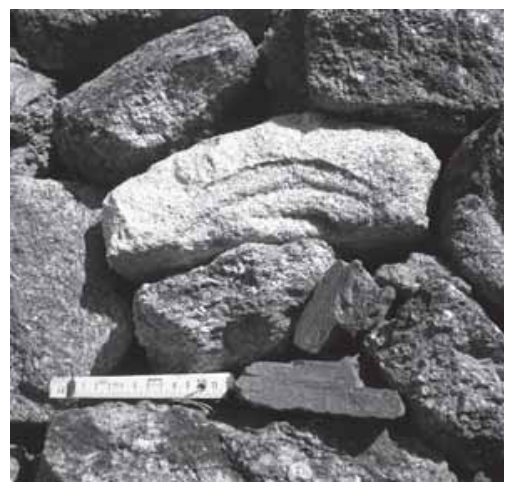

FIG. XXXI x $14 \mathrm{~cm}$. Granito gris claro.

\section{Morfología:}

Cabecera: semicircular con rueda fragmentada.

Bibliografía: Inédito

\section{VR-35 Ara votiva (Fig. XXXII y XXXIII).}

Ubicación actual: en una casa particular propiedad de los dueños de la Posada Real La Mula de los Arribes en la c/ Verónica. La pieza se encontraba formando parte de la cocina de la casa en rehabilitación donde se encuentra la pieza anterior (VR-34).

Dimensiones y material: $40 \times 20 \mathrm{x}$ $13 \mathrm{~cm}$. Granito.

\section{Morfología:}

Cabecera: Presenta dos molduras separadas que recorren toda la pieza y un coronamiento algo deteriorado

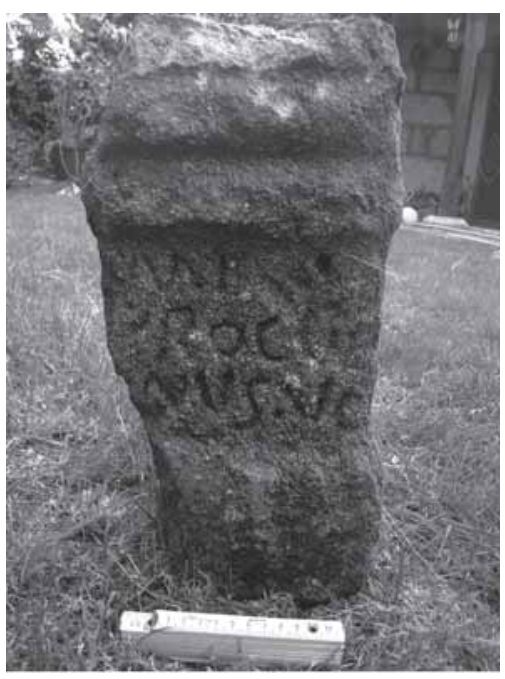

FIG. XXXII con dos pulvini. En su parte superior presenta un orificio rodeado de un círculo. 
Cuerpo: El campo epigráfico rebajado se encuentra deteriorado en sus laterales, afectando a la lectura de la primera letra de cada línea. Por otro lado presenta un agujero al final de la primera línea, posiblemente fruto de su reutilización, que ha provocado la pérdida de 3 ó 4 letras de la primera línea. Asimismo la pieza se encuentra fracturada en su parte inferior izquierda, con lo que la primera letra de la última línea se ha perdido.

Pie: simple

Transcripción y desarrollo: Nâb[iae] / Procull/ [i]nus · vo(tum)

Interpretación: A Nabia, Proculinus le dedicó este voto

Comentario: La lectura presenta dificultades evidentes para corroborar el teónimo propuesto. La opción de la divinidad Nabia es sugerente, ya que sí se aprecian las primeras letras y esta divinidad se suele asociar a fuentes

y cauces fluviales, que abundan en la localidad y que fluyen hacia el Duero. Asimismo en las cercanías del castro de San Mamede, de donde posiblemente procede la pieza hay una pequeña fuente termal. Más facilidades de interpretación presenta el antropónimo, Proculinus es un cognomen bien atestiguado por toda Hispania, como variación de Proculus y que presenta otras formas como Proclus o Proclinus. Estamos a la espera de poder realizar un calco que confirme nuestra lectura.

Datación: siglo I-II d.C.

Bibliografía: Inédito

\section{VR-36 Noticias de estelas}

Hemos tenido noticia de otras 5 posibles estelas en Villardiegua. Tres piezas estarían incrustadas en una casa de la localidad a la que no hemos tenido acceso y otras dos habrían sido trasladadas a Fariza. No ha sido posible aún su localización. 


\section{Pino del Oro}

PO 01 Estela funeraria (Fig. XXXIV) Ubicación actual: En la Finca Miralmonte, en Toro, en la carretera a San Marcos, junto a la ermita.

Procedencia: Se encontró en la ermita de San Esteban. Allí se bajó con el resto en el siglo XVIII de las ruinas de la ermita de Sancil o San Gil (cerro de El Picón) (Gómez Moreno, 1927, nº 84, p. 36).

Dimensiones y material: (85) x 46x 12 . Cortada en parte superior e inferior para usar como sillar.

\section{Morfología:}

Cabecera: Semicircular cortada para usar como sillar. Rueda con 8 ó 9 radios dextrógiros rodeada por moldura.

Cuerpo: Corte rehundido entre rueda y

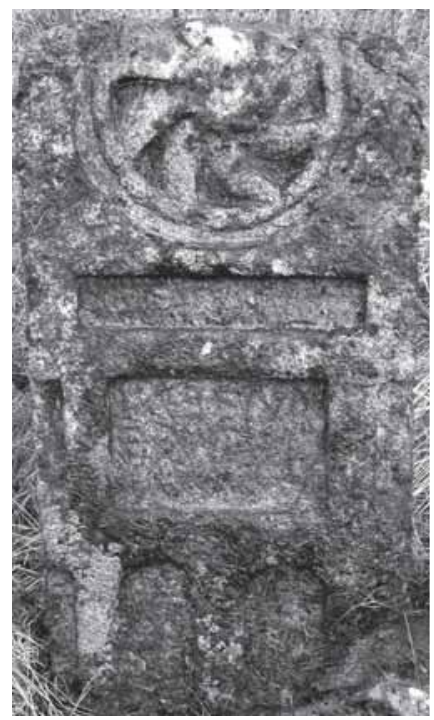

FIG. XXXIV cartela, pero poco rebajado. Cartela muy rebajada. Letras de 4,5 $\mathrm{cm}$ de alto. Columnas. Pie: arquería de medio punto con columnas

Transcripción y desarrollo: Labena/e Nati ${ }^{\text {/3 }}$ f(iliae) /ann(orum) $X X X$ Interpretación: De Labena, hija de Nato, de 30 años.

Comentario: Labena es un hapax, si bien existen otros casos como Laboena en Amendoeira (Macedo de Cavaleiros, BRA; HEp 7, $1172=$ ERRB 61) y formas como Lapoena y Lapona en Hinojosa de Duero, Salamanca (HAE 1285 y 1275), así como en Ocaña, Toledo ( $A E$ 1988, 829)) Natius solo existente también en Málaga $(A E 1985,505)$ y un Natiuos en Martos, Jaén (CIL II 1678), no así la forma Natalis, que es abundante en Hispania.

Tipología: II B

Datación: Siglos II-III (CIRPZa).

Bibliografía: Gómez MORENo, 1927, p. 36, nº 84;

Bragado 1991, nº 108, lám. LXII, 1; Bragado 1996, pp. 10-11, nº 1; CIRPZa 115; HEpOL 24855; CABALLER, 2007, nº 101. 


\section{PO 02 Estela funeraria}

Ubicación actual: Desconocida.

Procedencia: Encontrada a fines del siglo XIX en el Cerro de Sancil e incrustada en la «casa del moral» frente al pontón de la carretera (GómEZ Moreno, 1927); actual tienda al noroeste del puente.

Dimensiones y material: Pequeña.

\section{Morfología:}

Cabecera: Rueda de 8 radios.

Cuerpo: corto letrero

Bibliografía: Gómez MoReno 1927, p. 36, nº 83.

\section{PO 03 Estela trísoma}

Ubicación actual: Desconocida.

Procedencia: Pino del Oro. Según Masdeu servía de mesa de altar en la ermita de San Esteban (al igual que PO 06).

Dimensiones y material: desconocidas, posiblemente se tratara de brecha o "mármol de Santo Adrião" al igual que PO 06.

Morfología: desconocida

Transcripción y desarrollo: $D \cdot M /$ Calpurniûs $/{ }^{\beta}$ Severinus $\cdot e t /$ Reburina Cal/purniâe filiâe ${ }^{16}$ carissimae / memoria / an(norum) $\cdot$ XIIX

Variantes:

a) $\mathrm{D} \cdot \mathrm{O} \cdot \mathrm{M} /$ Calpurnius $/{ }^{\beta}$ Setwerivus $\cdot$ et $/$ Reburina Cal/purnioe filiae ${ }^{16}$ carissimae / memoria / an(norum) $\cdot$ XIIX (FITA)

b) $\mathrm{D}$ (iis) $\mathrm{M}$ (anibus)/Cal[p]urnius $/{ }^{3}$ Sewerivus et Reburi[ni]/a[e] Cal[p]urni/noe filioe cari $/{ }^{6}$ ssimae / memoria an(norum) XIIX (CIL)

c) $\mathrm{D}$ (iis) $\mathrm{M}$ (anibus) $/$ Calpurnus ${ }^{\beta}{ }^{3}$ Severin $<\mathrm{u}>\mathrm{s} /$ et Reburi/ae Calpurni/ nae filiae cari $/{ }^{6}$ ssmae / memoria / an(norum) XIIX (SEvILLano)

d) $\mathrm{D}$ (is) $\mathrm{M}$ (anibus) / Cal[p]urnius / Severinus / et Reburi[ni]/a Cal[p]urninae filiae cari/ssimae / memoria / an(norum) XIIX. (CABALler).

Interpretación: A los Dioses Manes. Calpurnio Severino y Reburina, [lo hicieron] en memoria de su queridísima hija Calpurnina, de 18 años. Comentario: Los padres dedicaron a su hija, en memoria, esta lápida. La reconstrucción del texto en el CIL parece errónea, ya que Reburina está en nominativo, y Calpurnia en dativo, son madre e hija. Es una inscripción de texto muy parecido a PO 06, lo que hace más factible la 
transcripción de Fita. Las versiones tampoco coinciden en las líneas de texto. El hecho de que la inscripción esté perdida no hace posible otra reconstrucción. Calpurnia parece más factible que su forma Calpurnina, ya que es muy frecuente la presencia de este nombre con más de 43 casos en su forma masculina y femenina, con ejemplos cercanos en Villalcampo (HAE 891), Muelas del Pan ( $A E$ 1982, 488), Babe (Bragança, EE IX, 277). El cognomen Severinus cuenta con más de 48 casos en sus diferentes formas repartidos por toda la Península. Reburina y sus variantes Reburrina y Reburinia cuenta con ejemplos cercanos en Villalcampo (HAE 890), Fresnadillo (Gómez Moreno, n 33 ) o Moral de Sayago (Gómez Moreno, $\mathrm{n}^{\mathrm{o}}$ 31), contando tan sólo con un ejemplo fuera de Zamora (en el cercano Hinojosa de Duero), lo cual nos puede indicar que se trata de un nombre de uso local.

Tipología: posiblemente como PO 6 (vid. infra)

Datación: Siglo II (CIRPZa).

Bibliografía: MASDEU 1775, 559; FITA 1885, no 82; CIL II 2614; ILER 3548; Sevillano 1978, p. 5, $\mathrm{n}^{\circ}$ 71; CIRPZa 117; HEpOL 8425; Caballer $2007, n^{\circ} 162$.

\section{PO 04}

Ubicación actual: Desconocido.

Procedencia: Pavimento de la ermita San Esteban.

Dimensiones y material: Recortada, de granito.

Morfología: letras de $7 \mathrm{~cm}$.

\section{Transcripción y desarrollo:}

Toutono / Elguisteß ${ }^{\beta}$ ri f(ilio) an(norum) L

\section{Variantes:}

a) Iovi Ono(bensi) El(ius) Guisieri f(ilius) an(imo) 1(ibens)

b) Iovi · Ono/el · Guisie/ri · f(ilio) · an(norum) - L (hedera) (FITA).

c) IOVIONO/EL·GVISIE $/{ }^{3} \mathrm{RIFANL} \cdot \mathrm{G}(C I L)$.

d) Ioviono / Elguiste/3ri f(ilio) an(norum) L O[...] (CIRPZa)

e) Ioviono / Elguiste/3ri f(ilio) an(norum) L (Gómez Moreno).

Interpretación: Ioviono, hijo de Elguisterio, de 50 años.

Comentario: Iovianus cuenta con un testimonio en Rocaforte, Navarra (IRM Nav 59) y en Galinduste Salamanca (HEp 3, 296), si bien en este último ejemplo se trata de una pizarra de época cristiana. En su forma Iovina en Coria del Río, Sevilla (CILA $3595=H E p$ 4, 676). Proponemos 
la lectura Toutuono para el nombre del fallecido por varias razones. En primer lugar Toutono es habitual en la zona con 3 casos conocidos en Villalcampo (HAE 923, HAE 927 y HAE 930), uno en Villalazán (CABALler GonzÁLez, 2007, n 37, esta inscripción es inédita) y un Totono en Villardiegua (VR-14), así como 4 casos en Castelo Branco y otros en Salamanca, Palencia y Barcelona. En segundo lugar es habitual en la zona la ejecución de la letra $T$ con una parte superior muy corta que podría dar la impresión de ser una I (vid. supra VR-07 o VR-19), especialmente teniendo en cuenta la dificultad que supone el uso del granito y el desgaste que tenía la pieza que se encontraba reutilizada en la ermita Por su parte Elguisterius/-us sería un hapax, tan sólo un caso parecido de Elgueni en genitivo en Villalcampo (HEp 7, 1085). Descartamos la posibilidad de que se trate de un ara a Júpiter, ya que sería el único testimonio en la zona y ni el formulario, ni la presencia en la parte final de la inscripción de las siglas f(ilio) y an(norum) nos llevan a apoyar esta teoría.

Bibliografía: MASdeu, 1775, 27; Fernández Duro, 1885, 78; FitA, 1885, no 82; CIL II 2613; Gómez Moreno 1927, p. 36, nº 85; ILER 154; Morán, 1944, p. 246, no 16; SeVillano 1978, nº 66; García 1991, p. 569 (add. $\mathrm{n}^{\mathrm{o}}$ 1); CIRPZa 114; HEpOL 8424; CABALLER 2007, $\mathrm{n}^{\circ} 161$.

\section{PO 05 Estela funeraria (Fig. XXXV)}

Ubicación actual: En la Finca Miralmonte de Toro, en el camino de San Román, junto a la ermita.

Procedencia: Ermita de San Esteban.

Dimensiones y material: Casi completa, $88 \mathrm{x}$ $39 \times 14$. Granito.

\section{Morfología:}

Cabecera: rueda de 6 radios curvos dextrógiros. Hay una moldura exterior enmarcando la cabecera, dentro de la cual se sitúa la moldura de la rueda. Rebaje horizonatal, tal vez redondeado, debajo de la rueda.

Cuerpo: cartela rebajada con esquinas dobladas. Posiblemente enmarcada por pilastras. Altura mayor de letras $5 \mathrm{~cm}$.

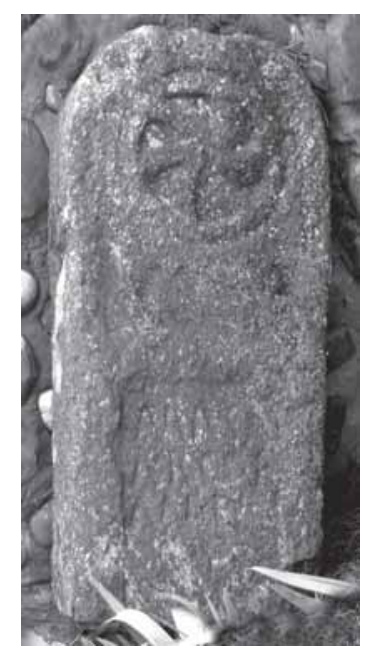

FIG. XXXV 
Pie: aparentemente se mantienen las molduras laterales de la cartela hasta el final.

\section{Transcripción y desarrollo:}

Mac(ana) / Arco(nis) f(ilia) / avn(orum) $L X$

Variantes: M(arco) Ac(ilio) / Arco(nis) f(ilio) ann(norum) L. FITA; MAC / ARCO F/ JWL (CIL).

\section{Interpretación:}

Mac(ana), hija de Arcón, de 60 años.

FIG. XXXV

Comentario: Mac[i]ana en cercano Moral de Sayago (ILER 2285). Pero podría ser Mac(ario/-a), Mac(enus/-a), el muy frecuente Macer o cualquier otra combinación posible. Arco muy común, se repite en Carbajales de Alba, Villalazán, Villalcampo (2) y Villardiegua de la Ribera (vid. supra VR 14, 19 y 25). Tipo de letra capital rústica con tendencia cursiva.

\section{Tipología: I C}

Datación: Por la ausencia de fórmula de consagración s. I.

Bibliografía: MASDEU, 1775, 27; FerNÁNDEZ DURO, 1885, 78; FITA, 1885, no 82; CIL II 2615; MoRÁN, 1944, nº 16, p. 246; Morán, 1946, p. 132; Morán, 1968, p. 111; Soria 1970, p. 587; ILER 2342; SEvilLano 1978, $\mathrm{n}^{\circ}$ 70; Bragado 1996, nº3, pp13-14; CIRPZa 116; HEpOL 8426; CABALler 2007, $\mathrm{n}^{\circ} 102$.

\section{PO 06 Estela trísoma (Fig. XXXVI)}

Ubicación actual: Finca Miralmonte en Toro, en el camino de San Román, km7, junto a la ermita.

Procedencia: Era la mesa de altar en la ermita San Esteban.

Dimensiones y material: $87 \times 56 \times 13$. Brecha o "mármol de Santo Adrião". Rota por parte superior, y probablemente en el lado izquierdo e inferior. Reciente rotura de lado inferior izquierdo.

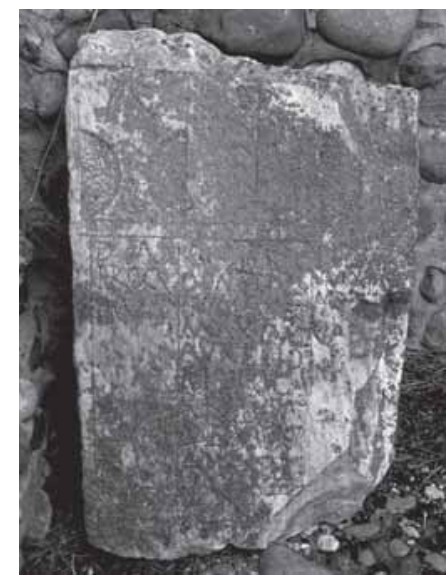

FIG. XXXVI 


\section{Morfología:}

Cabecera: cabecera triple, aunque fragmentada. Rueda de 6 radios sinistrógiros sobre un cuello que sirve de peana. En el centro hay una forma vegetal esquemática, que podría representar una conífera o una palma.

Cuerpo: líneas incisas marcan las cartelas. Letras de 3 y $2 \mathrm{~cm}$ de alto. Pie: probablemente liso. Tres arcos mal grabados según Gómez Moreno.

\section{Transcripción y desarrollo:}

A: $D$ (iis) $M$ (anibus) / Procu ${ }^{3}$ lo

B: D(iis) M(anibus) / Domitius / ${ }^{3}$ Proculus et / Maximina / Aurelio / ${ }^{6}$ filio cal rissimo / memoria / ân(norum) XXIII

C: $D$ (iis) M(anibus) / Maximi/ne

Variantes: B: D(iis) M(anibus) / Proculus et $/ 3$ Maximina / Aurelio / filio ca/ ${ }^{6}$ rissimo / memoria/m XXIII (CIL)

\section{Interpretación:}

A: A los Dioses manes, Proculo.

B: A los Dioses Manes, Domicio Próculo y Maximina en memoria de Aurelio, hijo queridísimo, de 23 años.

C: A los Dioses Manes, Maximina.

Comentario: Se antoja dudosa la resolución de las líneas 7-8. Podría interpretarse como un memoriam, memoria / an(norum) o memori(am) a/n(norum), aunque preferimos inclinarnos por la segunda opción. Aquí los sujetos están en dativo, y se trata de dos padres y su hijo. Estructura del texto muy parecida a PO 03. Tipo de letra capital rústica cursiva. Tanto los nomina Domitius y Aurelius, como el cognomen Proculus (séptimo más frecuente de Hispania) son nombres habituales en Hispania y presentes en la cercana localidad de Villalcampo. Maximina también es frecuente con ejemplos tanto en el conventus Emeritensis (Mérida, CIL II 585) como en el Astur (Astorga, CIL II 2640).

Tipología: III $^{5}$

Datación: La utilización del superlativo parece situar la estela a finales del s. II - s. III.

\footnotetext{
${ }^{5}$ Grupo III de la tipología de las estelas de brecha realizada por M. Navarro Caballero (1998). Según la tipología de Abásolo y García Rozas, también se podría clasificar dentro del grupo III, si bien la diferencia de material hace aconsejable una tipología aparte.
} 
Bibliografía: MASDEU, 1775, 485; FitA, 1885, nº 81; CIL II 2616; GóMEZ Moreno, 1927, nº 86, p. 37; Batlle 1963, no 92, p. 218; Sevillano 1978, nº 67-69, p. 4; Lión 1990, p. 563, nota 9, lám. IV, 2; Bragado 1996, nº 2, pp. 11-13; NAVARRo 1998, p. 195, nº 4; CIRPZa 118; HEpOL 8427; CABaller 2007, $\mathrm{n}^{\circ} 103$.

\section{PO 07 Estela funeraria (Fig.} XXXVII)

Ubicación actual: Museo de Zamora Procedencia: Encontrada en unas obras de alcantarillado.

Dimensiones y material: $41 \mathrm{x} 31 \mathrm{x}$ ? Granito rojo. Cubierto o partido en parte inferior. Solo se ve la cabecera y la parte superior del cuerpo epigráfico.

\section{Morfología:}

Cabecera: rueda en relieve con 6 radios dextrógiros. Franja horizontal con pequeño ángulo central en su parte superior.

Cuerpo: cartela rehundida entre columnas

Pie: arquería

Transcripción y desarrollo: Prim/o

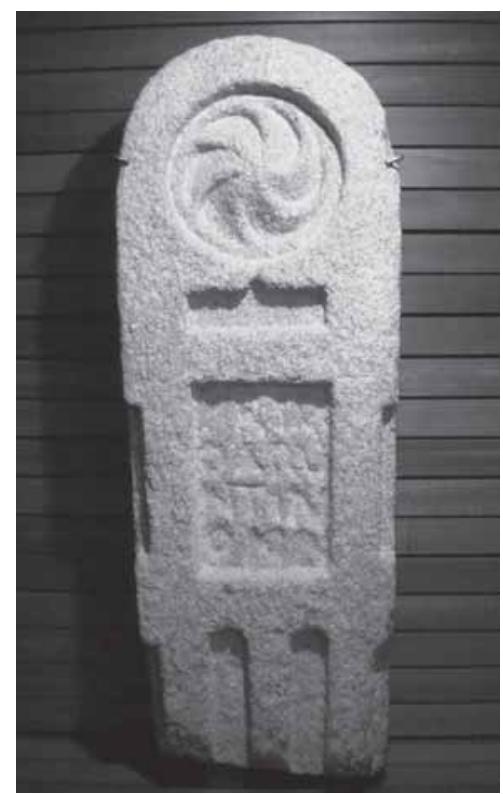

FIG. XXXVII Arư ${ }^{\beta}$ ntin/o ânn(orum) $L$

Variantes: Prim/o Ary $/{ }^{3}$ ntin/onn (Rodríguez Lorenzo)

Interpretación: A Primo, hijo de Aruntio, de 50 años

Comentario: Se podría pensar que en 1. 4, es $<A>N N$. Primus es un nombre documentado en el Hispania, si bien poco frecuente en el Noroeste. Aruntinonnius/-us es un hapax, y no tiene paralelos, lo que puede hacer dudar de la lectura facilitada por el primer editor, quizá se leyera Arantonius, antropónimo frecuente en la zona de Castelo Branco.

Tipología: II B

\section{Datación:}

Bibliografía: Rodríguez Lorenzo, 1993, p. 14, fig. 1; HEp 5, 883; CIRPZa 119; HEpOL 16094. 
PO 08 Estela funeraria (Fig. XXXVIII)

Ubicación actual: Dentro del patio de la casa en la c/Gamones 17.

Procedencia: En el muro de un edificio viejo, seguramente en la misma finca.

Dimensiones y material: $60 \times 33 \times 15$. Granito gris.

\section{Morfología:}

Cabecera: redondeada, con una rueda rehundida de cinco radios dextrógiros en bajorrelieve.

Cuerpo: cartela rectangular rehundida, flanqueada por pilastras. Ilegible y fragmentada

Bibliografía: Rodríguez LoRENZO, 1993, p. 14, fig. 2. Inventario de la JCyL 49-1570001-01, estela I.

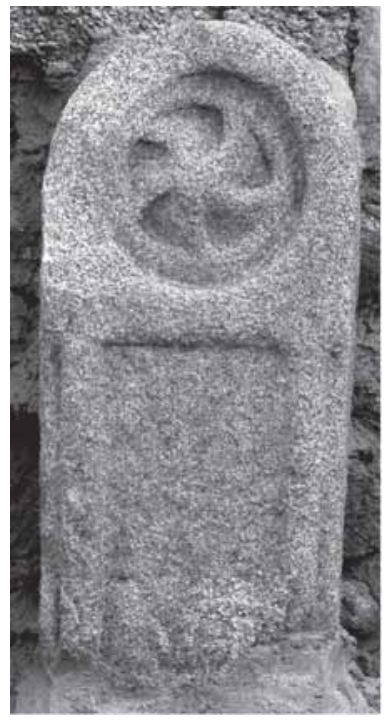

FIG. XXXVIII

\section{PO 09 Cabecera de estela (Fig. XXXIX)}

Ubicación actual: Sobre el dintel de una puerta, a 1,8m de altura, de un edificio de 1959 en c/El Otero. Dimensiones y material: (40) $\mathrm{x}$ (30) x ?. Solo se conserva la rueda de la cabecera. Granito gris.

\section{Morfología:}

Cabecera: redondeada con rueda de 12-13 rayos sinistrógiros. Podría haber una moldura exterior.

\section{Cuerpo}

Bibliografía: Rodríguez LoRENZO, 1993, p. 14, fig. 3.

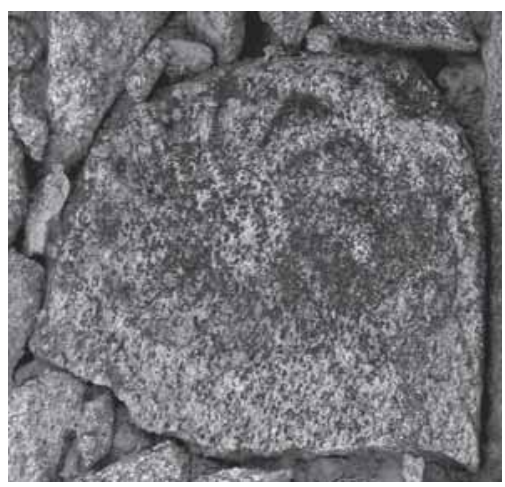

FIG. XXXIX

Inventario de la JCyL 49-157-000101 , estela III. 


\section{PO 10 Estela funeraria (Fig. XL)}

Ubicación actual: En la pared lateral de una casa antigua, en la c/La Fuente 1, a unos 5 metros de altura y en horizontal.

Dimensiones y material: $70 \mathrm{x} 20 \mathrm{x}$ ? (medidas aproximadas ya que no ha sido posible acceder a la pieza). Granito gris.

\section{Morfología:}

Cabecera: redondeada, con una rueda rehundida de 4 radios dextrógiros.

Cuerpo: Cartela cuadrada y rehundida, flanqueada por pilastras. Ilegible.

Pie: aparentemente sin formas.

Comentario: inaccesible

Bibliografía $^{6}$ : RodríGuez LoRENZO, 1993, p. 14, fig. 4. Inventario de la JCyL 49-157-

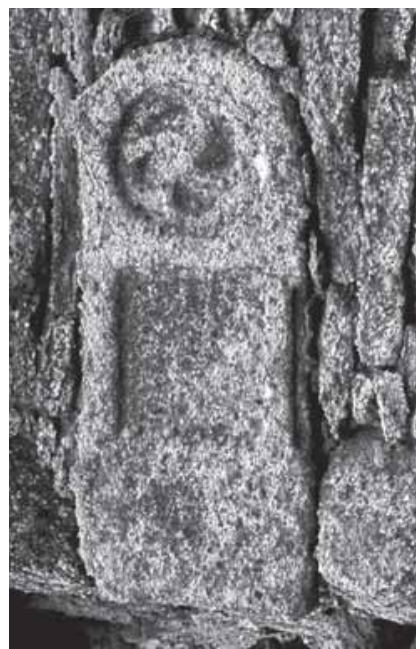

FIG. XL 0001-01, estela II.

\section{PO 11 Ara votiva (Fig. XLI)}

Ubicación actual: En el garaje de la casa de Domingo, concejal del ayuntamiento, el $\mathrm{n}^{\mathrm{o}} 1$ de la c/Concejo.

Procedencia: Servían sus mitades de adornos en la parte superior de los pilares de entrada de su propiedad, en un camino al lado sur del pueblo.

Dimensiones y material: Ara partida en dos. Granito gris moteado con rojo. (74) x 41 x 27 Se encuentra en dos partes que no casan entre sí, de modo que falta un fragmento intermedio.

\section{Morfología:}

Cabecera: dos pulvini y un frontón

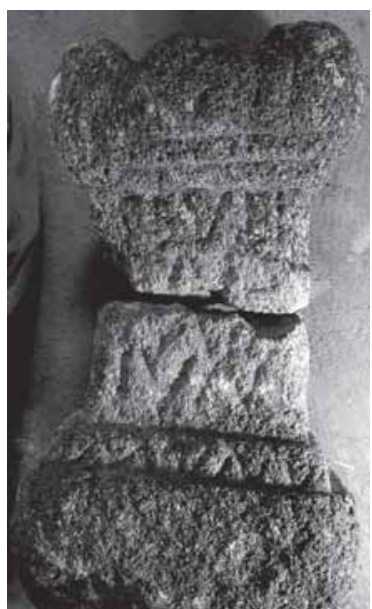

FIG. XLI redondeado sobre doble moldura escalonada. El pulvinus izquierdo se encuentra roto en su parte trasera y roto/rebajado en la delantera.

\footnotetext{
${ }^{6}$ Sobre la posible bibliografía anterior de esta pieza vid. infra PO 15.
} 
Cuerpo: cartela con unas dimensiones aproximadas de $30 \times 27 \mathrm{~cm}$, aunque la altura es una estimación puesto que está fragmentada.

Pie: doble moldura escalonada que da lugar a la base, poco desbastada y más ancha. Podría haber letras, que aparentan una decoración en triángulos, en la primera moldura.

Transcripción y desarrollo: Sever/ us [- - - / [- - ] /(ibens) v(otum) m(erito) Interpretación: Severo se lo dedicó de buena grado a ?

Comentario: Un exvoto sencillo ya visto en Rosinos de Vidriales (Zamora), aunque tampoco es descartable - ante las dificultades de lectura- que se trate de una inscripción funeraria. La decoración en la moldura primera podría leerse типи. Sin embargo es necesaria una autopsia en limpio para confirmar la decoración en greca.

También es posible que las dos piezas correspondan a dos inscripciones diferentes. Severus es un cognomen muy extendido por toda la Península Ibérica, con casos en la cercana Duas Igrejas (Miranda do Douro, BRA; $A E$ 1978, 578), si bien no cuenta con testimonios conocidos en la provincia de Zamora, aunque tenemos un Severinus en el propio Pino (PO 3).

Tipología: no es una estela.

Bibliografía: inédito. Inventario de la JCyL 49-157-0001-01, aras I y II.

PO 12 Cabecera de estela

(Fig. XLII)

Ubicación actual: Sobre dintel de ventana en semiesquina c/Los Pajares.

Procedencia:

Dimensiones y material: Cabecera de estela. (21) x $25 \times 8$. Granito gris. Morfología:

Cabecera: redondeada con rueda de 7 radios dextrógiros en relieve.

Bibliografía: inédito. Inventario de la JCyL 49-157-0001-01, estela VI.

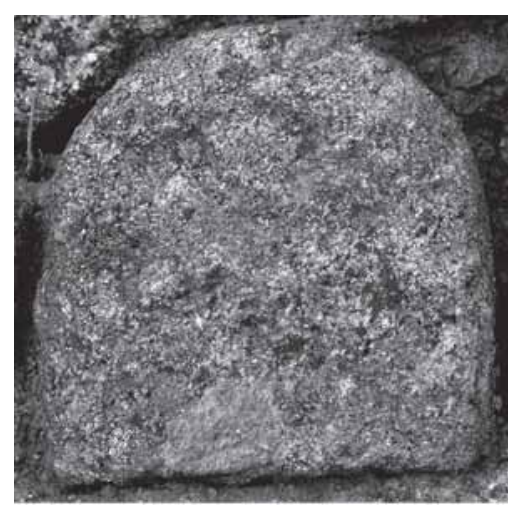

FIG. XLII 


\section{PO 13 Cabecera de estela} (Fig. XLIII)

Ubicación actual: En zona superior de muro lateral de una casa en c/ Calana, a 3-4 m de altura.

Dimensiones y material: Cabecera de estela de (35) x 35 x ?. Podría haber más, pero está tapado con argamasa todo salvo la rueda. Granito naranja pálido.

\section{Morfología:}

Cabecera: rueda con doble moldura, con 12 radios sinistrógiros.

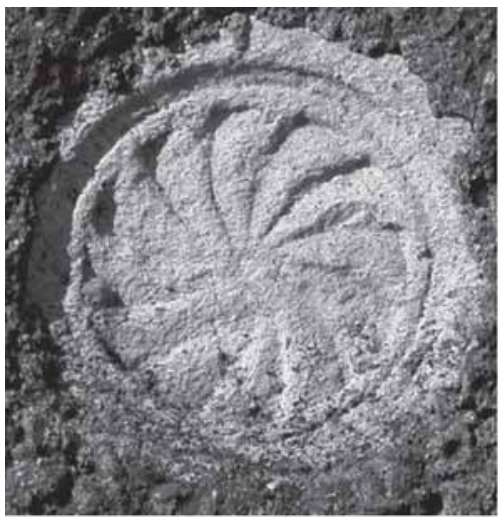

FIG. XLIII

Bibliografía: inédito. Inventario de la JCyL 49-157-0001-01, estela V.

\section{PO 14 Pie de estela (Fig. XLIV)}

Ubicación actual: Bajo ventana en la casa nueva junto a la Puente Chiquita, enmarcada por el diseño de la ventana.

Dimensiones y material: Inaccesible. Granito anaranjado.

\section{Morfología:}

Dos molduras rehundidas que parecen corresponder al pie de una estela. Podría ser un caso parecido a VR 23, aunque en este caso casi no habría cabecera

Bibliografía: inédito

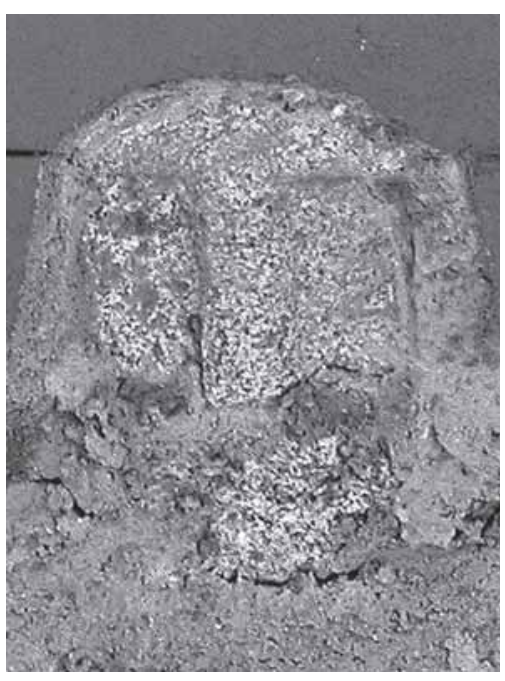

FIG. XLIV 
PO 15 Estela funeraria (Fig. XLV) Ubicación actual: incrustada en el muro externo del patio de una casa nueva en la c/La Llaga, a $0,7 \mathrm{~m}$ sobre la calle.

Dimensiones y material: $51 \times 36 \mathrm{x}$ ?. Granito rojo. Cubierto o partido en parte inferior. Solo se ve la cabecera y la parte superior del cuerpo epigráfico.

\section{Morfología:}

Cabecera: rueda en relieve con 6 radios dextrógiros.

Cuerpo: cartela rehundida.

Transcripción y desarrollo: $P[\mathrm{E}, \mathrm{T}$ o $\mathrm{R}] \ldots / \ldots$

Bibliografía: inédito. Inventario de

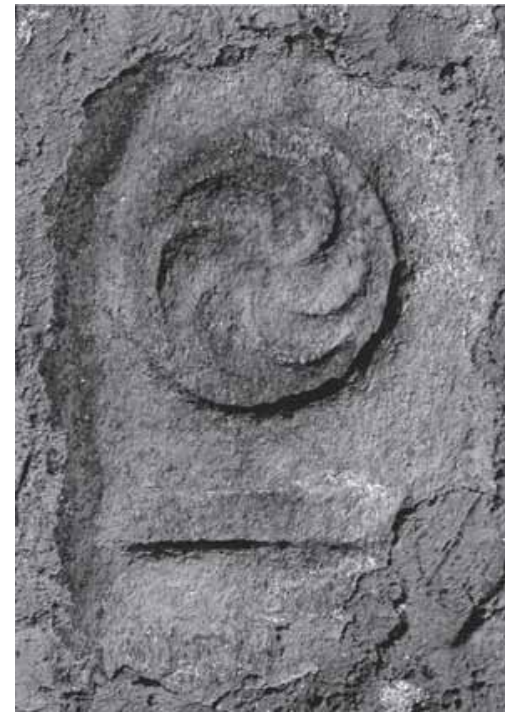

FIG. XLV la JCyL 49-157-0001-01, estela IV.

\section{PO 16 Noticia de estelas}

Gómez Moreno da noticia de otras 5 estelas de las que apenas conocemos datos, 3 de ellas aparecieron en una cortina al norte del pueblo, incluyendo una completa con epitafio legible, si bien fueron utilizadas para la construcción de la puerta de un pajar por lo que se perdieron. Asimismo relata el hallazgo de otras dos estelas que se encontraban junto a un sepulcro, con cabecera semicircular y campo epigráfico, aunque dudosos vestigios de letras, y rueda de 4 rayos curvos (GÓMEZ MORENO 1927, nº 82 y 83). La última de estas piezas bien pudiera corresponderse con PO 10. 


\section{REFERENCIAS}

Abascal, J. M. (1994): Los nombres personales en las inscripciones latinas de Hispania, Madrid.

AвÁsolo, J. A. (1973): «Nuevas urnas “en forma de casa” procedentes de Poza de la Sal (Burgos)», BSAA 9, pp. 434-443.

(1977): «Las estelas decoradas de la región de Lara de los Infantes: estudio iconográfico», BSAA 43, pp. 61-97.

AbÁsolo, J. A. - García Rozas, R. (1990): «Sobre las estelas romanas y su ornamentación», [en]: Actas del Primer Congreso de Historia de Zamora (Zamora, 14-18 de marzo de 1988), Tomo 2, Zamora, pp. 561-569.

AbÁsolo, J. A. - Marco, F. (1995): «Tipología e iconografía en las estelas de la mitad septentrional de la Península Ibérica», [en]: F. Beltrán (ed.), Roma y el nacimiento de la cultura epigráfica en Occidente, Zaragoza, pp. 327-59.

Alarcão, J. DE et alii (1990): "Appendice. Propositions pour un nouveau tracé des limites anciennes de la Lusitanie romaine», Les villes de Lusitanie romaine. Hiérarchies et territoires (Table ronde internationale du CNRS. Diciembre 1988), Paris, pp. 319-330

Alonso, F. (e.p.): «Diálogos en el paisaje de la muerte olvidada», [en]: Actas de las Jornadas de Jóvenes en Investigación Arqueológica: Dialogando con la cultura material (septiembre de 2008).

Alonso, Á., CRESPO S. (2000): Corpus de inscripciones romanas de la provincia de Zamora. Fuentes epigráficas para la historia social de Hispania romana $(=C I R P Z a)$. Salamanca.

Batlle Huguet, P. (1963): Epigrafía latina, Barcelona.

Benito del rey, L. - Grande del Brio, R. - Martín García, R. - García Diego, A. J. - Lera Maillo, J. C. (1987): «El castro de San Mamede, en Villardiegua de la Ribera (Zamora): nuevos descubrimientos arqueológicos», Studia Zamorensia 8, pp. 41-51.

Bragado, J. M. (1990): «Aproximación al estudio de la red viaria romana en la provincia de Zamora», [en]: Actas del I Congreso de Historia de Zamora (marzo, 1998), Zamora, pp. 379-408.

(1991): Fuentes literarias y epigráficas de la provincia de Zamora y su relación con las vías romanas de la Cuenca del Duero, León.

(1996): «Aportaciones a la epigrafía romana de Zamora», Studia Zamorensia 3, pp. 9-29. 
CABALlER, M J J. (2007). La teonímia y onomástica personal indígena y romana de la provincia de Zamora según las Fuentes Epigráficas, (Tesis Doctoral), Valencia.

CIRPZa. $=$ Alonso y CRESPO 2000.

Corbier, M. (1991): «L'écriture en quête de lecteurs», Literacy in the Roman World, Sup. Journal of Roman Archaeology, 98-118.

Corzo, R. (1986): San Pedro de la Nave. Estudio histórico y arqueológico de la iglesia visigoda, Zamora.

Cumont, F. (1942): Recherches sur le symbolisme funeraire des romains, Paris. ERRB $=$ REDENTOR 2002

Esparza, A. (1986): Los castros de la Edad del Hierro del Noroeste de Zamora, Zamora.

Fernández Duro, C. (1885): «Antigüedades de la Villa del Pino (Zamora)», BRAH 6, pp. 77-84.

FITA, F. (1885): «Antigüedades de la Villa del Pino (Zamora)», BRAH VI.

García Martínez , S. M. (1999): «Los zoelas: sociedad y antroponimia», Brigantia, 19, 1-2, p. 17-36.

Gómez Moreno, M., (1927): Catálogo monumental de España. Provincia de Zamora, Madrid.

(1904): “Sobre arqueología primitiva en la región del Duero" BRAH 45, 147 160.

Goody, J. (1986): The Logic of Writing and the Organization of Society. (Studies in Literacy, Family, Culture and the State), Cambridge.

Hodder, I. (1986): Reading the Past. Cambridge.

ILER = VIVES 1971-72.

Le Roux, P. - Tranoy, A. (1984): «L'épigraphie du nord du Portugal: bilan et perspectives», Conimbriga 23, pp. 19-41.

Lión, M. C. (1990): «Aspectos decorativos e onomásticos de las estelas funerarias del occidente de Zamora». [en]: Actas del Primer Congreso de Historia de Zamora (Zamora, 14-18 de marzo de 1988),. Tomo 2, Zamora, pp. 561-569.

MacCormack, S. (2003): «Loca Sancta» en C. Ando (ed.): Roman Religion. Edinburgh: 252-72.

Martín Carbajo, M. Á. - Sanz garcía, F. J. - Marcos Contreras, G. J. Misiego Tejada, J. C. - Del Caño garcía, L Á. - Redondo Martínez, R. Martín Maeso, Ma E. (2001): «Actuación arqueológica en el castro de San Mamede o peña Redonda, en Villardiegua de la Ribera (Zamora)», Anuario del Instituto de Estudios Zamoranos Florián de Ocampo 18, pp. 27-39.

Mañanes Pérez, T. - Solana Saínz, J. Ma (1985): Ciudades y vías romanas en la Cuenca del Duero, Valladolid. 
Martín García, R. - García Diego, A. J. (1990): «Aproximación al estudio de la escultura zoomorfa de la provincia de Zamora: los verracos», Studia Zamorensia XI, pp. 17-37.

Martín VAlls, R. (1975): «Variedades tipológicas en las esculturas zoomorfas de la Meseta», Studia Archaeologica 32, pp. 69-92.

Masdeu, J. F. (1775): Historia critica de España y de la Cultura española (Tomo 19), Madrid.

Moreno Gallo, I. (2006): «Vías romanas de Astorga”, en Nuevos elementos de ingeniería romana», [en]: III Congreso de las Obras Públicas Romanas. León, pp. 23-65.

NAGY, L. (1943): Les symbolismes astraux sur los monuments funeraires de la population indigene de la Pannonia. Laureae Aquicensis (Dissertationes Pannonicae serie $\left.2^{\mathrm{a}} \mathrm{II}\right)$.

Navarro Caballero, M. (1998): «Las estelas en brecha de Santo Adrião: observaciones tipológico-cronológicas», BSAA 64, pp. 175-206.

OLSON, D.R. (1994): The world on paper. The conceptual and cognitive implication of writing and reading, Cambridge.

Ong, W. J. (1982): Orality and Literacy. The Technologizing of the Word. Routledge, Londres.

Pereira Menaut, G. (1995): «Epigrafia “política” y primeras culturas epigráficas en el Noroeste de la Península Ibérica», [en]: F. Beltrán (ed.), Roma y el nacimiento de la cultura epigráfica en Occidente, Zaragoza, pp. 293-327

Pérez Rodríguez-Aragón, Fernando (1993): «Las estelas funerarias de época tardoantigua en la mitad Norte de la Península Ibérica», BSAA 59, pp. 183198.

Rabanal Alonso, M. A.(2006): «Las vías romanas en las provincias de Zamora y León», [en]: Actas del II Congreso de Historia de Zamora (Noviembre, 2003), Zamora, pp. 439-456.

Redentor, A. (2002): Epigrafia romana da região de Bragança (= ERBB), Lisboa.

Rodríguez Lorenzo, J. (1993): «Cuatro estelas romanas ¿Una prolongación de la GL30? Y una apostilla final», El Miliario Extravagante 44, pp. 14$-17$.

SÁnchez-Palencia, F.-Javier (ed.) (2000): Las Médulas (León). Un paisaje cultural en la Asturia Augustana, León.

SÁnchez-PAlencia, F.J.- Ruiz del Árbol, M. (1999): «La minería aurífera romana en el Nordeste de Lusitania: Las Cavenes de El Cabaco (Salamanca)», AEspA 72, pp. 119-140.

Sande Lemos, F. de (1993): Povoamento romano de Trás-os-Montes oriental (tesis doctoral inédita), Universidade do Minho, Braga. 
Sastre Prats, I. (2001): Las formaciones sociales rurales de Asturia romana. Madrid.

(2002): Onomástica y relaciones políticas en la epigrafía del conventus Asturum durante el Alto Imperio, (Anejos de AEspA XXV), Madrid.

Sastre, I.; Beltrán, A.; Sánchez-Palencia, F. J. (2009): «Nuevo pacto de hospitalidad procedente de Pino del Oro (Zamora)», ZPE 168, pp. 287292.

Sevillano Carbajal, F. V. (1970): «La calzada de Miranda en Zamora y sus puentes», BSAA. 36, pp. 475-484.

(1978): Testimonio Arqueológico de la provincia de Zamora, Zamora.

Soria SÁnchez, V. (1970): «De arqueología cacereña», [en]: XI Congreso Nacional de Arqueología (Mérida, 1968), Zaragoza, pp. 568-590.

Tranoy, A. (1982): La Galice romaine. Recherches sur le nord-ouest de la Péninsule Ibérique dans l'Antiquité, Paris.

(1984): «Ateliers lapidaires et niveaux de culture dans le Nord du Portugal», Gallaecia 7-8, pp. 269-274.

Vives, J. (1971-1972): Inscripciones latinas de la España romana, Barcelona $(=I L E R)$. 